\title{
Copyright
}

by

James William Smith

2012 
The Dissertation Committee for James William Smith certifies that this is the approved version of the following dissertation:

\section{Can Investors Fully Adjust for Known Biases in Manager Communications?}

\section{Committee:}

Lisa L. Koonce, Supervisor

Shuping Chen

Marlone D. Henderson

D. Eric Hirst

Michael G. Williamson 


\title{
Can Investors Fully Adjust for Known Biases in Manager Communications?
}

\author{
by
}

James William Smith, B.S.; M.P.A.; M.S.Acc.

\author{
Dissertation \\ Presented to the Faculty of the Graduate School of \\ The University of Texas at Austin \\ in Partial Fulfillment \\ of the Requirements \\ for the Degree of \\ Doctor of Philosophy
}

The University of Texas at Austin

August 2012 


\section{Dedication}

To my family 


\section{Acknowledgements}

I am extremely thankful for the constant support and encouragement of my dissertation advisor, Lisa Koonce. She has been instrumental in my growth and development and I will be forever grateful for her guidance. I appreciate the assistance from the faculty at the University of Texas at Austin. In particular, I acknowledge the contributions from the members of my dissertation committee; Shuping Chen, Marlone Henderson, Eric Hirst, and Michael Williamson. Also, my fellow doctoral students at the University of Texas at Austin have had a tremendous influence in my progression. I have greatly benefited from the assistance of such gifted individuals.

This dissertation has benefitted from feedback from Patrick Badolato, Brett Cantrell, Jeffrey Hales, Peggy Jimenez, Volker Laux, Tracie Majors, John McInnis, Todd Thornock, Jeff Wilks, and David Wood. I also thank participants at workshops in the following universities- University of Alberta, University of Kentucky, Georgia Tech, Iowa State University, and University of Texas at Austin for their insightful comments and suggestions. I gratefully acknowledge the financial support of the Donald D. Harrington Fellows Program, the Eugene and Dora Bonham Fund, the Chartered Accountants Education Foundation of Alberta, the UHY Mann Frankfort Stein \& Lipp Advisors, Inc. Endowed Excellence Fund in Accounting, and the Department of Accounting at the University of Texas at Austin.

I thank my parents for their assistance and encouragement. In particular, my mother always taught me that I could become anything that I wanted to become. Then, even when I no longer believed her, she continued to believe in me. I thank my children for their unconditional love. They fill my life with joy. Finally, I thank my beautiful wife, Stephanie. She makes me better in every way. Her enduring patience and unselfish care have allowed me to pursue this path. I am eternally grateful for her. 


\title{
Can Investors Fully Adjust for Known Biases in Manager Communications?
}

\author{
James William Smith, Ph.D. \\ The University of Texas at Austin, 2012
}

Supervisor: Lisa L. Koonce

Managerial communications often contain biased information because of managerial incentives and other influences. A common assumption in the accounting literature is that if investors are aware of managerial biases, they will be able to fully adjust for those known biases when reacting to managerial communications. Drawing on insights from psychology, I experimentally document that investors are not able to fully adjust for known biases in managerial communications - even when investors know the quantitative amount of the manager's bias. Indeed, investors behave contrary to economic theory as they are unable to fully unravel the effects of known biases when rendering judgments about the firm. My study has implications for researchers, regulators, and investors. 


\section{Table of Contents}

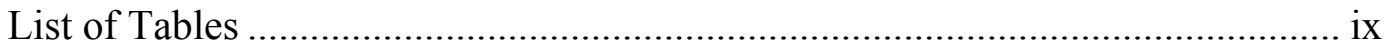

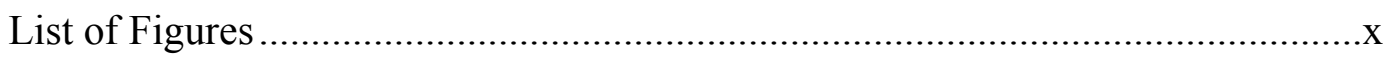

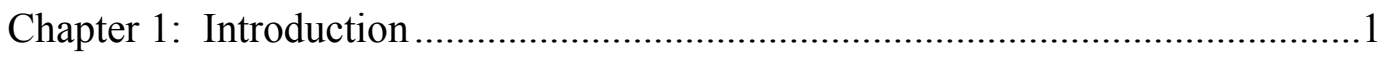

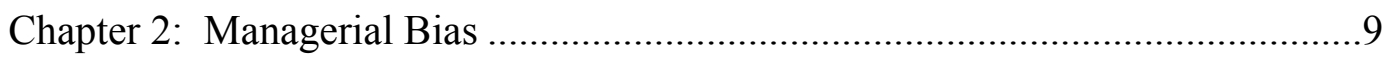

2.1 Determinants of Bias in Managerial Communications ..............................

2.2 Consequences of Bias in Managerial Communications...........................10

Chapter 3: Theory and Hypothesis Development ................................................13

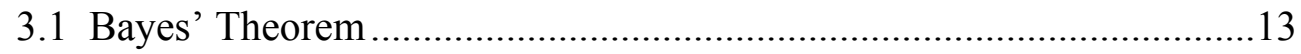

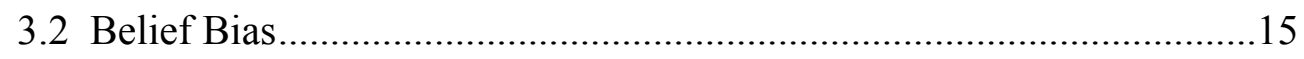

3.3 Will Investors Always Demonstrate the Belief Bias? .............................17

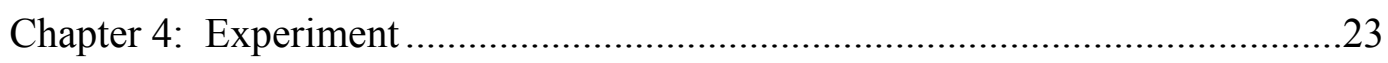

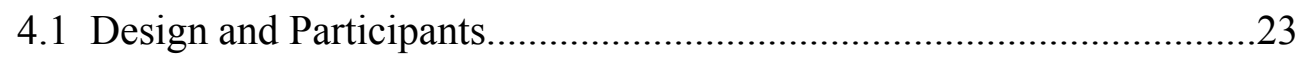

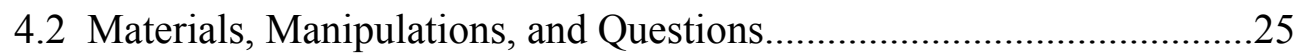

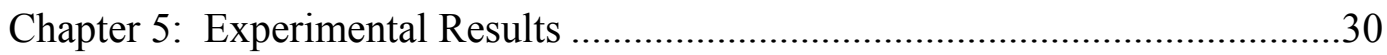

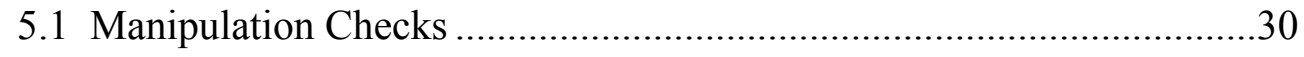

5.2 Hypothesis Testing...........................................................................

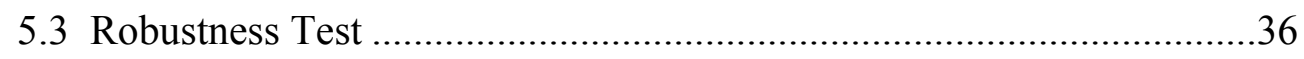

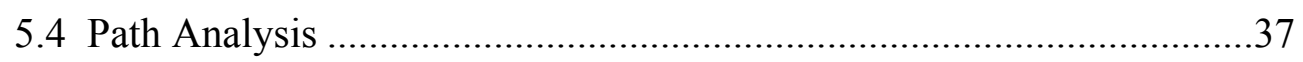

5.5 Possible Reconciliation of Results for Judgments and Investment Decisions

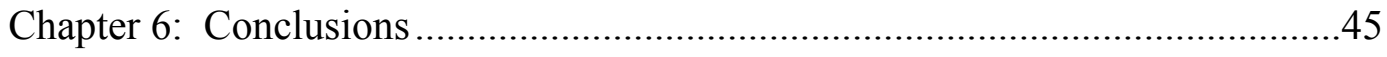

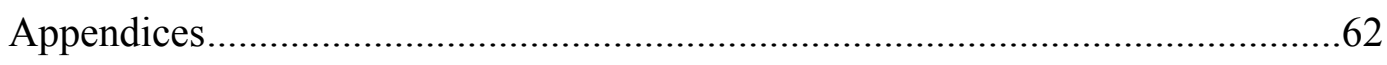

Appendix A: Experimental Materials ………………………………........63

Appendix B: Experimental Manipulations ..................................................66

Appendix C: Experimental Questions .....................................................73

Appendix D: Questions About The Press Release.........................................78 
Appendix E: Additional Process-Related Questions ....................................80

Appendix F: Manipulation Check And Demographic Detail Questions .....83

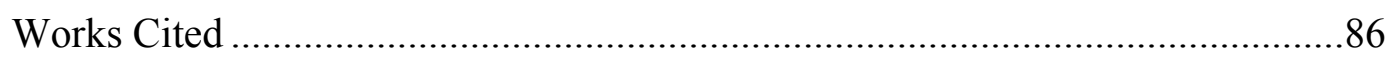

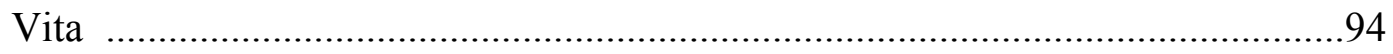




\section{List of Tables}

Table 1: Manipulation Check Results..............................................................48

Table 2: Main Experimental Results.............................................................49

Table 3: Robustness Results ...........................................................................51

Table 4: Believability of Manager Explanations and Credibility of Manager

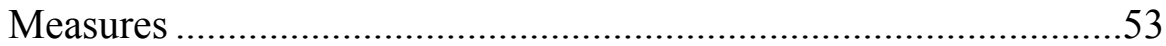




\section{List of Figures}

Figure 1: Situational Factors Influencing Information Reliability ......................55

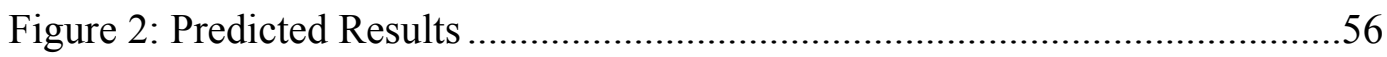

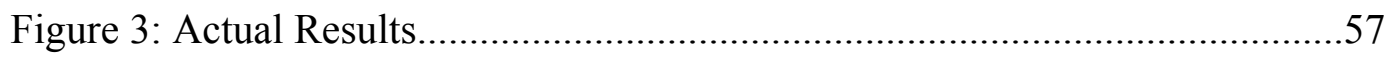

Figure 4: Structural Equation Model as Predicted by the Belief Bias ..................58

Figure 5: Structural Equation Model Results................................................60 


\section{Chapter 1: Introduction}

Firm managers regularly provide information to current and potential investors. For example, managers often describe forthcoming company projects or provide expectations for future sales growth. The venues for communicating this information include financial reports, conference calls, and press releases. These communications provide information for investors to make buy, sell, and hold decisions (Leuz and Verrecchia 2000). Although this information can inform investors, the information may be biased. Biased communications can be caused by many factors, including employment contracts tied to financial measures (Bamber, et al. 2010), performance expectations set by the market (Bernard and Skinner 1996; Daniel, et al. 2002), and financial reporting requirements (Aboody, et al. 2004). Although a common assumption is that investors can and will fully adjust for known biases (Dechow and Skinner 2000; Schipper 2007), my study challenges this assumption.

Providing data on the issue of whether investors will be able to fully unravel managerial bias is important for several reasons. First, most analytical models and empirical tests indicate that individuals are rational (i.e., Bayesian) information processors and, thus, will be able to successfully unravel managerial bias in earnings, voluntary disclosures, and other communications (Stein 1989). The literature notes that the only circumstances where unraveling is not likely is when information regarding the bias - such as the details of managerial incentives - is not available to investors (Dye 1988) or, if available, the information is too coarse to identify the bias (Kanodia, et al. 2004). Although these ideas appear to be widely accepted, to my knowledge, they have 
not been subject to empirical testing. Second, if investors (and others) are not able to fully adjust for known biases, their judgments about management and their communications are likely to be very different. For example, if investors cannot fully adjust for managerial incentives, they are likely to overvalue a firm when a highly incentivized manager provides positive news.

In this paper, I develop predictions based on two theories from psychology and then conduct an experiment to test the hypothesis that, in most cases, investors will be unable to fully adjust for known biases in managerial communications. Specifically, I first draw on theory indicating that individuals will automatically accept a communication as being truthful as part of the process of comprehending it (Gilbert 1991). This tendency, which I term the belief bias, indicates that individuals have a tendency to believe plausible information, even when other evidence suggests the information is unreliable or false (Evans, et al. 1983; Markovits and Nantel 1989). This result occurs because as individuals comprehend the information, they are overly focused on the content of the information and are not sufficiently attentive to indicators of the veracity of the information (Gilbert, et al. 1993; Burgoon, et al. 2008). I hypothesize that investors will be prone to the belief bias except in one limited circumstance-namely, when the bias in the communication is represented in quantitative terms and the investors' judgments also are in the same quantitative terms. In this circumstance, the investors' judgments are scale compatible with information about the bias (Fischer and Hawkins 1993; Tversky, et al. 1988; Slovic, et al. 1990). Scale compatibility theory from psychology suggests that investors should be able to fully adjust for managerial bias 
in circumstances where the managerial bias is explicitly quantified (i.e., known and precise) and investors render compatible quantifiable judgments.

I conduct an experiment using a $2 \times 3$ between-participants design. Study participants take the role of an investor who is working for an investment management firm and evaluating a company as a potential investment. I manipulate the valence of the company's communication (e.g., including an earnings forecast) at two levels-whether the company manager discloses favorable or unfavorable information that could potentially update the investor's evaluation of the firm. In addition, I manipulate (at three levels) the degree to which the manager is known to be biased. In the low bias condition, investors are told that the manager's prior disclosures have not been biased. The other two levels of this manipulation involve situations where investors know that the manager's prior forecasts have always been biased. The two high bias conditions differ though, in whether or not the bias is described in quantitative terms. In the high bias / qualitative information condition, the bias is described in only qualitative terms (i.e., investors know that the manager has historically issued inaccurate forecasts). In the high bias / quantitative information condition, the bias is described, not only in qualitative terms, but also in quantitative terms (i.e., the actual earnings have always been five cents per share different from the manager's forecast). Thus, in this condition, investors not only know that the information is unreliable but they know precisely the extent to which the information has always been biased.

I employ two main dependent measures. While both of these measures require investors to assess the company's financial prospects for the year, the response scale 
differs between the two. One measure asks study participants to generate a quantitative prediction of earnings for the period. In contrast, the second dependent measure asks a qualitative question — namely, how favorable the company's actual earnings will be. ${ }^{1}$ Using two measures is important as it allows me to test investor susceptibility to the belief bias when the response scale matches or does not match the information about the manager's bias. An additional measure asks participants how likely they are to buy or sell shares in the company. This measure allows me to test the potential influence that the belief bias can have on investing decisions.

My results reveal that, consistent with my predictions, investors do not fully unravel (in their earnings judgments) for the impact of managerial bias, even when the impact of that bias is precisely known. Specifically, I document that investors in the low bias conditions render judgments that are consistent with the valence of the company's communication. That is, those receiving a favorable disclosure from the manager with no known biases forecast higher earnings and assess earnings as more favorable than those receiving an unfavorable disclosure. Here, investors (appropriately) believe that the disclosed information accurately reflects the economic realities of the company. For the high bias conditions, when investors know that the firm manager is biased but are only provided with qualitative information regarding that bias, participants' judgments nevertheless reflect the biased information (i.e., they do not unravel the bias). As

\footnotetext{
${ }^{1}$ In this dissertation, I use the terms qualitative and quantitative for two purposes. First, I use these terms to refer to how the manager's bias is known - that is, in qualitative or quantitative terms. Second, I use these terms to explain how the investor evaluates the firm - that is, in either qualitative or quantitative terms. In both of these contexts, the term quantitative refers to a numerical representation of the firm's earnings per share while qualitative descriptions and judgments do not include numerical earnings per share representations.
} 
predicted, the latter occurs whether their responses are in a quantitative or qualitative form. Most interesting, though, I find that even when investors know that the firm manager is biased and also know the quantitative amount of that bias, investors are still unable to fully unravel the bias even when they are asked to provide a compatible quantitative forecast. In the latter situation, my predictions based on scale compatibility theory suggest that investors should be able to fully unravel the manager's bias as the numerical amount of the bias is explicitly given (e.g. five cents per share) and the investor provides a revised forecast in a compatible quantitative format. Although study participants know the quantitative magnitude of the bias, they do not fully adjust for the bias in their judgments regarding the company. That is, both their qualitative and quantitative assessments of the firm do not fully unravel the known biases in manager communications. This finding suggests the strength and robustness of the belief bias.

The results for the investment decision are mixed. Consistent with their earnings judgments, investors are more likely to invest when given favorable information as compared to unfavorable information in the case of either low bias or high bias (where the qualitative nature of that bias is known). That is, their investment decisions follow their beliefs about earnings. However, when there is high bias and the precise quantitative nature of that bias is known, investors' decisions for both the favorable and unfavorable conditions do not significantly differ - that is, they act as though they unravel the bias. Given that the earnings judgments in this high bias / quantitative situation revealed that investors did not fully unravel the bias, it is somewhat surprising that these investment decision results do not show a similar pattern. 
It is possible to speculate on an ex post basis as to why the different decision results occurred. Of course, future research should test the validity of such speculation. With this caveat in mind, the following explanation includes one possible reason for the apparent inconsistency between investor judgments and decisions. Research has documented that when individuals are asked to make a choice, they often anticipate any regret that their choice might cause in the future and then seek to avoid that regret to the extent possible (Reb 2008). This regret aversion results in a more careful and analytical decision making process. Thus, when asked to make investment decisions (which, in my experiment, were made after the earnings judgments), investors with quantitative information about the bias may have revisited the available case information and unraveled the effects of the known managerial bias when making their investment decisions. Although those investors in the high-bias / qualitative information conditions also may have revisited the case information once they were asked to make investment decisions, they were unable to fully unravel the bias without knowing the precise quantitative effect of the manager's bias.

My paper advances the scholarly literature in economics, accounting and psychology. As previously noted, economic theory assumes that the market will fully unravel the effects of managerial bias if two conditions are met (Stein 1989). Specifically, investors must know about the bias and the information about it must be sufficiently precise so that they can adjust for the bias. I find that even when investors have this information, they do not fully unravel for the effects of the bias. Thus, my paper provides important insights regarding this important assumption made by economic 
scholars. Second, my paper adds to accounting research by providing possible insights into research findings that appear to be inconsistent with economic intuition (Rogers and Stocken 2005; Piotroski and Roulstone 2004). For example, Barth, et al. (2010) show that analysts tend to rely on managers pro-forma earnings guidance despite managers' known incentives to opportunistically eliminate expenses from such guidance. My study suggests that this effect may be due to analysts' inability to fully discount for the known incentives of those managers. Third, my study adds to psychology literature by demonstrating another situation where judgment errors — due to biased information—are difficult to avoid. Gilbert, et al. (1993) suggests that unraveling can only occur when an individual devotes sufficient resources to the task, has sufficient logical abilities, and obtains the correct information. My study indicates that judgment errors may be impossible to avoid, even when these conditions appear to be met.

My paper has implications for researchers, regulators, and investors. For researchers, my study can allow them to make more-informed predictions regarding the influence of firm communications on investor judgments. For example, knowing that investors will not fully adjust for managerial incentives, researchers should expect investors to overvalue a firm when a highly incentivized manager provides positive news. My results suggest that analytical models in accounting should consider incorporating the impact that these biased communications have on investor judgments. For regulators, my study demonstrates that managerial communications influence investor judgments despite obvious biases that reduce the reliability of these communications. Given the impact that biased communications can have on investor judgments, the role of regulators in limiting 
the disclosure of unreliable information becomes ever more important. Finally, investors should be mindful of the apparently strong tendency to underweight the bias found in managerial communications when making judgments.

The remainder of this dissertation is organized as follows. Chapter 2 provides a brief overview of managerial bias. Specifically it addresses the potential biases that exist in managerial communications and details how prior literature often relies on the assumption that investors will fully adjust for known biases. Chapter 3 presents the theoretical motivation for this study and then develops my hypothesis. Chapters 4 and 5 discuss my experimental methods and results, respectively. Chapter 6 offers concluding remarks. 


\section{Chapter 2: Managerial Bias}

Firm managers play an important role in determining the information disclosed about a firm. Their knowledge concerning a firm's operations and their beliefs about a firm's future performance can impact the information disclosed. For example, a manager with knowledge about upcoming supply shortages can communicate this information to current and potential investors. Without managerial disclosure, this information might not be accessible to investors when considering investment opportunities. Managerial disclosure of this information would provide investors with information that could help better predict the firm's future cash flows and earnings (Kothari, et al. 2009).

\subsection{Determinants of Bias in MANagerial CoMmunications}

Although managers often truthfully convey firm-specific information to the markets, they also have incentives to bias certain disclosures. These biases can result from specific characteristics of the manager (e.g. manager is always optimistic or pessimistic) or from characteristics of a manager's situation that cause a manager to behave in a particular way. ${ }^{2}$ For example, employment contracts with financial incentives linked to firm performance often cause firm managers to bias their forecasts (Bushman and Indjejikian 1993; Bamber, et al. 2010; Bryan, et al. 2000). Market expectations for positive earnings and earnings growth have been consistently shown to bias firm managers' financial reports (Bartov, et al. 2002; Matsumoto 2002; Burgstahler

\footnotetext{
2 While biased behavior has been demonstrated in multiple contexts, all situational influences do not necessarily lead to biases. For example, a manager may disclose more information to the public because the market is demanding greater reporting transparency. Here, the manager's situation influenced the manager's behavior (e.g. his company disclosed more information), but the information is not necessarily biased.
} 
and Dichev 1997). Reporting decisions can be biased by accounting standards (Aboody, et al. 2004). Macro-economic factors specific to industries also can cause managers to behave in a biased fashion when communicating with the markets (Piotroski and Roulstone 2004).

Given the evidence suggesting managerial communications often are biased, it is logical to consider the potential consequences that such biases may have on investor judgments. In short, bias in information reduces the reliability of that information (FASB 1980). As explained in more detail in section 3.1, reliability of information is essential for the information to be useful. When forecasting a firm's financial performance investors must consider the potential decrease in the reliability of information as a result

of known biases (Maines and Wahlen 2006). At the extreme, communications may be so biased that the information is completely unreliable and, thus, uninformative. In this case, investors should disregard the information in making their decisions. Figure 1 provides a schematic representation of the relationship between situations that result in biased information and reliability of information. The figure provides several examples of situations that may result in managers communicating biased information. Although my experiment focuses on one of those situations (i.e. managerial biases), my findings arguably could have implications for other situations where there are biases in managerial communications.

\subsection{CONSEquences of Bias in MANAgerial CoMmunications}

Research in economics has long maintained that when investors can anticipate a firm manager's attempts to manage earnings, the investors will appropriately adjust for 
the earnings manipulation (Jensen 1986). Analytical models indicate that rational (i.e., Bayesian) investors will fully adjust for expected reporting bias (e.g. earnings management) when the bias is known and when there is sufficient detail to analyze the bias (Stein 1989; Chen et al. 2007).

Much of the literature in accounting follows these ideas in economics - namely, that managerial bias is only problematic for investors when the size and/or direction of the bias are unknown (Dechow and Skinner 2000; Richardson, et al. 2010). Accounting studies have long suggested that if investors know the implications of the information they receive (i.e. know how managerial bias influences the information), they will find the efficient price for the firm (Fama 1970, 1998). For example, when modeling earnings management (a specific example of bias in managerial communications), analytical researchers generally assert that all known information is incorporated into investor judgments (Dye 1988; Trueman and Titman 1988; Verrecchia 2001). Thus, these models predict that when investors know of a manager's propensity to bias information, the intended effects of earnings management (i.e. increasing the value of the firm) are unattainable.

Despite the maintained assumption that investors will be able to fully unravel managerial bias, several accounting studies reveal instances where investors fail to fully unravel the bias. While many of these studies offer different ideas for why this might occur, they do not or are unable to test these ideas. In some cases, accounting studies provide no explanation for the observation that investors have not fully unraveled managerial bias and remain silent as to why investors do not unravel. For example, 
Bamber, et al. (2010) find that firm managers often make predictably optimistic forecasts, but that analysts fail to fully adjust for this predictable bias in their own forecasts. This failure is attributed to a lack of sufficient resources on the part of analysts. Herrmann and Thomas (2005) attribute this result to some analysts being less informed, while Abarbanell and Lehavy (2003) are silent as to why analysts do not fully adjust (also see Barth, et al. 2010 and Hugon and Lin 2010). Bolton, et al. (2006) propose that when investors are overconfident or inattentive, financially incentivized managers will benefit from opportunistically managing earnings. Richardson, et al. (2010) suggest that transaction costs can play a large role in non-normative investor behaviors. In a review of financial reporting studies, Beyer, et al. (2010) call for further research into why analysts may not adjust for earnings management.

In large measure, these studies both implicitly and explicitly suggest that investors ought to adjust for known information (including information about managerial biases), if they were not constrained by other factors (e.g., insufficient resources, overconfidence, inattentiveness, or transaction costs). One objective of my study is to provide experimental evidence as to why this occurs. In addition, I hypothesize that even when the typical constraints to investors unraveling abilities are lifted (e.g. investors have all information about the firm and managerial biases, they have sufficient time and resources, and there are no transaction costs), investors will still fail to fully adjust for managerial bias. The following chapter describes the important theoretical foundation for my predictions and hypothesis. 


\section{Chapter 3: Theory and Hypothesis Development}

Managers communicate with current and potential shareholders to provide information pertinent to the firm. Investors use managerial communications (e.g., financial forecasts, financial statements, and press releases) to decide whether to invest in a specific firm (or sell currently held shares). Regulatory authorities in the United States have encouraged firms to increase their communications with investors and provide them with more transparency regarding internal firm operations (SEC 2003). In responding to this encouragement, firms have extensive latitude as to the form and content of their communications. While these communications can provide investors with decision useful information, the information often is biased, as previously explained. Investors are cognizant that certain constraints (e.g., managerial incentives, market expectations, and reporting requirements) exist but the influence that these constraints have on managerial communications may not be adequately considered when investors are making judgments about a firm.

\subsection{BAYES' THEOREM}

How investors should fully adjust for known biases is perhaps most easily seen through the lens of Bayes' theorem, a commonly accepted, normative model of belief revision (Fischhoff and Beyth-Marom 1983). Bayes' theorem describes how beliefs should change in response to new information. Posterior beliefs are a function of prior beliefs and the likelihood ratio (Posterior beliefs $=$ Prior beliefs $\times$ Likelihood Ratio). Prior beliefs refer to an individual's beliefs before receiving the new information. The likelihood ratio indicates the diagnosticity of new information for informing an 
individual's beliefs (Birnbaum and Stegner 1979; Beyth-Marom and Fischhoff 1983). As explained in more detail below, diagnosticity (and, thus, the likelihood ratio) is a function of the relevance and reliability of new information. ${ }^{3}$ That is, both the relevance and reliability of new information influence the degree to which an individual's prior beliefs are updated to his posterior beliefs. When the new information is either completely irrelevant or completely unreliable, the new information is non-diagnostic and an individual's posterior beliefs should be the same as his prior beliefs.

Returning to the idea that investors should be able to fully adjust for known biases, consider the following example. Assume an investor is considering an investment in a company. He searches out the most recent earnings forecast available for that company to help in forecasting the company's earnings for the year. The investor will have prior knowledge about the company and will use that knowledge in conjunction with any additional information from the earnings forecast to update his beliefs about the firm. To assess diagnosticity, this new information must first be evaluated based on its relevance to the investor's decision. ${ }^{4}$ Assuming the information is judged as relevant, the information is considered diagnostic pending an assessment of its reliability.

Now, assume that the communication from the firm manager is biased. In this situation, the diagnosticity of the communication is reduced via lower reliability, even

\footnotetext{
${ }^{3}$ Birnbaum and Stegner (1979) look at similar concepts in discussing source credibility. They introduce a third component related to the one's point-of-view. In my study, I ask all participants to take the role of employees in an investment firm, who are independent of management making the disclosures. As such, participants in my study are all asked to evaluate the scenario from an investor's point-of-view. Because I consider only investor's point-of-view, here I only discuss reliability and relevance as components of diagnosticity.

${ }^{4}$ Archival evidence suggests that investor reactions to managerial communications are stronger as the relevance of the information in the communications increases (Baginski, et al. 2004, Rogers and Stocken 2005). This finding is consistent with predictions based on Bayes' theorem.
} 
though it still remains relevant. As the reliability decreases, the new information should result in less revision of the investor's prior beliefs as compared to unbiased (i.e., reliable) information. ${ }^{5}$ In the extreme case where the information is completely unreliable, the information is non-diagnostic. Bayes' theorem suggests that the new information should, in this case, have no impact on the updating of an investor's prior beliefs. The investor should, according to Bayes' theorem, ignore the new information. This action results in posterior beliefs that are the same as their prior beliefs.

In summary, if managerial communications contain information that is either irrelevant or entirely unreliable for preparing a financial forecast, the information is nondiagnostic for the investor's task. Accordingly, as predicted by Bayes' theorem, investors' posterior beliefs should be equal to their prior beliefs in this circumstance.

\subsection{BELIEF BIAS}

Although the Bayesian framework is a useful tool in which to consider the impact of bias in a communication, it is silent on whether investors will or will not appropriately consider the bias. I turn to psychology to address this issue.

I draw on theory indicating that as an individual comes to comprehend new information, they automatically believe that information (Gilbert 1991). In this paper, I

\footnotetext{
${ }^{5}$ The weighting of prior beliefs and the likelihood ratio (including both the reliability and relevance of new information) may not always be Bayesian-efficient. Individuals may mistakenly place too much or too little weight on prior beliefs or on the likelihood ratio. For example, when investors overweight prior beliefs and thus underweight likelihood ratio from a Bayesian perspective, the updated beliefs are conservative (Philips and Edwards 1966). The post-earnings announcement drift has been attributed to investors being slow to update their new beliefs because they underweight the relevance that current earnings have on future earnings (Jacob, et al. 1999). In this case, the prior beliefs are weighted more heavily than predicted by Bayes' theorem.
} 
refer to this tendency as the belief bias $^{6}$ (Markovits and Nantel 1989). Psychology research suggests that one of the primary reasons individuals are so susceptible to the belief bias is that believing is an automatic process that occurs as we acquire and learn new information. When comprehension occurs, individuals spontaneously and effortlessly accept the information received as truthful. The process of examining the merits and validity of new information occurs only after initially believing (Gilbert 1991). In other words, comprehension of new information and believing that information are not separable processes; rather, they occur simultaneously. For example, an investor reads an article about a firm's newly implemented manufacturing system that will reduce construction costs. The investor reads the information and automatically believes that the new system will reduce costs.

At first blush, this belief bias seems logical and rational (and, thus, does not seem to be a bias at all). However, the problem is that the information provided may be incorrect. Additional information or contemplation may suggest that an individual ought to disbelieve the information. This disbelieving is not an automatic process and only occurs after the initial comprehension and belief that the information is truthful (Gilbert, et al. 1993). Even then, this deliberative process of disbelieving does not necessarily override the initial belief (Wilson, et al. 2000). In other words, the initial, automatic belief can persist even in the presence of contrary evidence. Indeed, it is potentially very robust.

\footnotetext{
6 This type of bias is quite different from managerial bias previously discussed. This belief bias refers to a tendency that people have to automatically accept information as truthful, while managerial bias refers to unreliability of managerial disclosures.
} 
This belief bias can cause important changes in subsequent behavior. For example, subsequently received information often is interpreted so that it seems consistent with prior, albeit erroneous, beliefs (Russo, et al. 1996; Jones and Sugden 2001). Thus, individuals do not always question the content or source of new information, particularly without compelling and salient evidence that would suggest reassessing the initial information. Without ready access to contradicting information, an individual is prone to accepting the initial information as the truth and makes little attempt to find evidence contrary to his belief. For example, when a salesman details the superior features of a particular product, potential buyers often fail to adequately consider the salesman's incentives to only present favorable features of the product, ignoring the product's subpar characteristics (Gilinsky and Judd 1994). Thus, the potential buyer believes that the product is better than actually warranted. In this situation, the buyer fails to fully account for the bias created by the salesman's incentives, even though the incentives are known to produce a less reliable description of the product. In summary, the belief bias is a psychological phenomenon in which individuals have a tendency to believe information they learn even when additional evidence should cause one to question the reliability of that information (Evans, et al. 1983).

\subsection{Will InVestors Always Demonstrate the Belief Bias?}

The belief bias is an innate tendency that has proven robust across multiple scenarios (Gilbert 1991). For example, individuals are influenced by feedback, even when that feedback is known to be invalid (Ross, Lepper, and Hubbard 1975). That is, individuals provided with positive (negative) feedback on their performance for a specific 
task assess their abilities to be more (less) favorable, despite knowing that the feedback provided was invalid. People have a propensity to begin by believing and only secondarily question the validity of information. It is perhaps not surprising that the effect has proven to be strong. Prior research has demonstrated that errors caused by innate (i.e., hard-wired) tendencies are rarely mitigated by incentivizing individuals (Camerer and Hogarth 1999). ${ }^{7}$ Because the belief bias is a memory-based error (i.e., the individual cannot retract from memory the initial understanding of the communication), it is unlikely that incentives to increase one's effort or instructions to "think hard about the biased source" would succeed in eliminating the error (Arkes 1991). When individuals are unaware of the bias, increasing effort or thinking more about the task presented may increase confidence in the judgments. However, without knowledge of the bias, the cognitive bias will remain.

Interestingly, while some research has shown that the belief bias may be attenuated, no research has documented the elimination of this bias. For example, when details regarding the unreliability or bias in information are made more salient, individuals adjust more for the bias (Millar and Millar 1997). However, the adjustment is not complete, as the belief bias is only moderated and not eliminated. Gilbert, et al (1993) provides three necessary criteria for individuals to correct erroneous beliefs. First, an individual must have the logical abilities. Second, the correct information must be provided. And third, an individual must have the motivation and cognitive resources to

\footnotetext{
${ }^{7}$ In accounting and finance, it is commonly argued that any errors in individuals' judgments will cancel out in a multi-person market setting. However, biased individual judgments have been previously shown to persist for extended periods and in the aggregate, resulting in biased market prices (Ganguly, et al. 1994).
} 
perform the task of disbelieving the erroneous belief. The prevalence of these three factors can influence the degree to which individuals adjust their judgments for known biases. For example, when an individual is performing a difficult task and does not possess the cognitive capacity to perform the task, he is less likely to appropriately correct for any errors. Even when the three criteria are met, I argue that individuals may still be unaware of the errors in their beliefs and remain unable to fully adjust their judgments for any known biases.

Will, then, individuals never be able to fully unravel for known bias? Drawing on another literature within psychology, termed the scale-compatibility literature, I posit that there may be another situation which may, in fact, lead to the elimination of the belief bias. Notably, this other situation is largely out of the individual's control, in contrast to the ideas of Gilbert, et al. (1993). The basic idea in the scale-compatibility literature is that information is given a greater weight in judgment if it is naturally compatible with the scale of the response-for example, if the attribute and response scale are measured in the same units (Slovic, et al. 1990; Tversky, et al. 1988).

To illustrate this idea, consider the following study by Schkade and Johnson (1989). In it, participants are asked to make two judgments related to a specific gamble (i.e., the chance to win a certain amount of money). Participants are asked how much they would be willing to pay to take the gamble (i.e., a price) and how attractive the gamble is to them (i.e., a rating). These two judgments are on different response scales. The price is in monetary units, or dollars, and the rating is on an attractiveness scale. The study results show that participant preferences depend on the response scale. When 
responding with a price they are willing to pay for the gamble, participant responses are higher (i.e. they seem more likely to take the gamble) for a gamble that could result in large payouts with low probability of winning as compared to small payouts with a high probability of winning. In contrast, when asked to rate the attractiveness, participant responses indicate the opposite as they focus on the probability of winning the gamble. That is, the gamble for a large payout with low probability of winning is less attractive than the gamble for a small payout with a high probability of winning. The authors suggest that these findings are based on the compatibility of the response scales to the information provided. The pricing response scale is more compatible with the amount of money (they are both in dollars) while the attractiveness ratings scale is more compatible with the probability of winning. Thus, participant responses are significantly associated with the monetary payout when asked to provide a price for a gamble and significantly associated with the probability of success when asked to give an attractiveness rating for a gamble.

Drawing on these ideas in the scale-compatibility literature, I hypothesize that whether an investor will be able to fully unravel managerial bias depends not on only whether they know the dollar magnitude of the bias but also on the nature of their response scale (i.e., whether it is compatible with that dollar magnitude of the bias). Thus, in the situation where an investor has information about the quantitative magnitude of the bias and the evaluation of the firm is in a compatible quantitative format (i.e., an earnings forecast), then the investor is likely to make a full correction for the known bias. For example, if an investor knows that earnings are biased upwards by five cents, he may 
be able to adjust his own forecast downward by five cents as compared to the manager's forecast. I further posit, however, that this full correction may only occur when scale compatibility exists. Accordingly, when the same investor makes a qualitative assessment regarding a firm's earnings (e.g., favorability judgments of the company's earnings), the investor's judgments should continue to demonstrate the belief bias.

Furthermore, when the investor only knows the direction of the bias - that is, he has qualitative information about the bias and, thus, does not know its dollar magnitude, he will be unable to make a full correction for the bias despite the compatibility of scales. That is, recall that a necessary condition for unraveling is that the impact of the manager's bias be precisely known (i.e., the precise dollar amount change that the bias will cause must be available). Thus, when an investor only has qualitative information about the bias, then he cannot unravel. Stated differently, scale compatibility has no opportunity to work in a situation where the impact of the bias is not precisely known.

That scale compatibility is the key construct (and not just the quantitative nature of the bias) is illustrated by a recent study on college admissions. Moore, et al. (2010) show that college admissions staff cannot fully unravel the influence that grade inflation has on an applicants' incoming grade point average. Specifically, applicants with inflated grade point averages are more likely to be accepted into a college program. This finding persists, despite the fact that admission decision-makers have complete knowledge regarding the distribution of grades from the applicants' prior college and have the opportunity to make necessary calculations to provide matching adjusted grade comparisons between applicants. These researchers demonstrate that an important 
qualitative judgment for graduate schools — namely, admission to a graduate program—is biased even when the explicit magnitude of the bias (i.e. the grade inflation) is known. In other words, this study indicates that having access to the quantitative magnitude of the bias is insufficient to eliminate the cognitive bias. That is, it also may be necessary to have scale compatibility, as I test in my study.

Taken together, this discussion leads to the following two-pronged hypothesis:

Hypothesis 1a: Investors' judgments, both qualitative and quantitative, about the firm's future prospects will be higher (lower) in the favorable (unfavorable) conditions when managerial communications have low bias as compared to high bias.

Hypothesis $1 b$ : Investors will only be able to fully adjust for biased information received from firm managers when the investors are provided with the quantitative value of manager's bias and are asked to make (scale-compatible) quantitative judgments about the firm's future prospects.

My a priori expected results for investors' quantitative and qualitative judgments regarding a potential investment are graphically depicted in Figure 2.

In summary, based on the belief bias and scale-compatibility theory I expect that, except in limited situations, investors will be unable to unravel the effects of known managerial biases when making earnings judgments. Only when investor judgments are made on a scale that is compatible with the effects of the bias and the effects of the bias are known with precision, will investors be potentially able to unravel for the known bias. 


\section{Chapter 4: Experiment}

\subsection{Design ANd Participants}

I conduct an experiment using a $2 \times 3$ between-participants design to test my hypothesis. Participants take the role of investors working for an investment management firm. As part of their role, they are evaluating a specific company as a potential investment. Participants receive a press release provided by the chief executive officer (CEO) of the company. I vary, at two levels, whether the press release includes information that is favorable or unfavorable for the company's current year earnings. This information suggests to investors that an updated earnings forecast may be required. I also vary, at three levels, the extent of the manager's bias in the information being communicated via the press release. In the low bias condition, the investors are told that the prior forecasts from the company's CEO have been fairly accurate. In the two high bias conditions, investors are told that the CEO has historically issued inaccurate forecasts. Specifically, investors learn that the CEO has always issued forecasts that have been biased in the same direction. That is, the CEO has been either consistently optimistic or consistently pessimistic in all of his previous forecasts. As explained in more detail below, the two high bias conditions differ in whether or not the information about the bias includes the specific quantitative magnitude for the bias. The two information favorableness conditions and three bias conditions are fully crossed with participants being randomly assigned to one of the six experimental conditions. ${ }^{8}$

\footnotetext{
${ }^{8}$ I purposely do not employ a $2 \times 2 \times 2$ experimental design, where favorable/unfavorable information, low/high bias, and quantitative/qualitative information are varied as independent variables. Investigating the effects of the belief bias in low-bias conditions with quantitative favorable and unfavorable information
} 
Participants include 150 Masters in Business Administration students enrolled in a top-20 business program. Sixty-two percent of these participants have previous experience with investing in common stock. In addition, participants in my study have on average 4.9 years of prior work experience and they have completed an average of 3.6 finance courses and 2.7 accounting courses. I believe that my participants possess the requisite accounting and financial knowledge to proxy for investors in my experimental task (Elliot, et al. 2007).

Participants were recruited via an e-mail request to students enrolled in the Masters in Business Administration program in the fall 2011 semester. All participants were assured that participation was voluntary and would not influence their standing in their courses or in the school. There is no deception of any kind used in this experiment. Participants were invited to complete the study within a specified time frame over a twoday period. To complete the study, participants presented themselves to the experimenter and were then provided with the experimental materials. Completion of the experiment took between 15 and 20 minutes and each participant was paid $\$ 10$ for their time. In addition, participants were entered in a random drawing for one of five prizes of $\$ 100$. All responses are anonymous as participant names are never recorded on the experimental materials. All collected information is kept in a secure, locked location.

(i.e., the two cells my current design is omitting) is unlikely to yield additional insights pertinent to my objective of determining when investors adjust for known biases. 


\subsection{Materials, Manipulations, AND Questions}

Participants are provided with background information regarding the company being considered for investment. The background material includes the consensus analyst forecast for the company from the prior month of $\$ 1.26$ per share. Appendix A includes a copy of the background materials used in my experiment. Participants are then given a press release from the company's CEO. In the favorable (unfavorable) information conditions, the CEO's updated forecast is \$1.31 (\$1.21) per share for the year. Further in the favorable (unfavorable) condition, the CEO also provides several reasons why the earnings per share forecast should be higher (lower) than the consensus forecast.

There are several important features of this favorable/unfavorable information manipulation. First, each of the reasons the CEO provides is stated in a way that indicates they represent the beliefs or expectations of company management and are not confirmed events applicable to the company's operations that are being newly released. This approach allows the reasons provided to remain plausible as an explanation for potential updates to the company's earnings per share forecast without conveying the reasons as externally verifiable facts, such as emerging economic trends or known cost reductions (Hutton, et al. 2003). Using externally verifiable facts would not measure investors' responses to managerial beliefs but rather their responses to relevant and previously unknown facts. Because the information represents the beliefs of management, this information is subject to any managerial biases that exist. Second, the favorable and unfavorable conditions explanations are, to the extent possible, symmetric. 
For example, in the favorable conditions the CEO explains: "We believe that the company's profit margins will improve." Alternatively, in the unfavorable conditions the CEO explains: "We believe that the company's profit margins will weaken." (See Appendix B for all of the details from the experimental manipulations.) Immediately following the news release, participants are provided with the bias manipulation. I operationalize the bias by manipulating the historical accuracy of the CEO's forecasts. Specifically, in the low bias conditions, the investors know that the CEO has provided fairly accurate forecasts in the past. In the high bias / qualitative information condition, the investor is told that the prior forecast updates have always been fairly inaccurate. Finally, in the high bias / quantitative information condition, the investor knows that the CEO's updates have always been fairly inaccurate and that the actual earnings have always differed by exactly $\$ 0.05$ per share. In both high bias conditions, the CEO is known to have provided forecasts that were consistently biased in the same direction. That is, the CEO has always been optimistic or he has always been pessimistic in the company's forecasts of earnings. ${ }^{9}$

After being presented with this information, all participants then respond to the two primary dependent measures. First, they assess the favorability of the company's

\footnotetext{
${ }^{9}$ For two reasons, I do not use financial incentives to operationalize the bias manipulation. First, it is difficult, if not impossible, to manipulate managerial incentives and also retain a fully crossed experimental design. That is, incentives leading to high bias for favorable forecasts (e.g., bonus paid based on expected stock price) are typically different from those incentives leading to high bias for unfavorable forecasts (e.g., stock options with a strike price based on expected stock price). In my design, I am able to use the same type of bias in both the favorable and unfavorable information conditions. Second, manipulating financial incentives does not allow me to argue that the bias is completely uninformative. That is, to test whether investors fully adjust for bias in managerial communications, the bias must render the disclosed information entirely unreliable. Even when managers have financial incentives to bias, the information they report may contain some degree of information content.
} 
earnings for the current year on a scale from 0 (very unfavorable) to 100 (very favorable). This dependent measure is the qualitative-scale response. Next, using an open-ended scale, they provide their own forecast for company's current-year earnings per share. This dependent measure is the quantitative-scale response. ${ }^{10}$ In addition to these two dependent measures, I ask participants to estimate a price-earnings (PE) multiple for the company. The question is open-ended (that is, no scale is provided to record responses), however, participants are told that companies in the industry typically have priceearnings multiples of between 10 and 20 .

After these judgment questions, I also ask participants to respond to two questions regarding decisions that they would likely make regarding the company's stock. These questions provide information regarding how the belief bias may influence investment decisions. First, I ask participants to consider how likely they would be to buy or sell shares in the company. For this question, participants respond on a scale with endpoints of -50 (very likely to sell) and 50 (very likely to buy). The mid-point on the scale, zero, is labeled as "not at all likely to buy or sell." Participants were also asked a second question regarding their potential investment decision. This second question asks participants how many shares they would buy or sell given they had enough funds to buy 10,000 shares of the company. For this question, participants record their response on a scale with endpoints of $-10,000$ (I would sell 10,000 shares) and 10,000 (I would buy 10,000 shares). The mid-point of the scale ( 0 ) is labeled as "I would not buy or sell any

\footnotetext{
${ }^{10}$ In a pilot study including 90 accounting students, I varied the order of the qualitative and quantitative judgment questions in the experimental materials (i.e. half of the participants made the quantitative earnings judgment first while the other half made the qualitative judgment first). The order of the questions had no significant impact on the participants' responses in the pilot study. Consequentially, I keep constant the order of the questions in this experiment.
} 
shares." Appendix C includes each of the questions previously described, just as participants received them while completing the experiment.

Additional questions are designed to capture the degree to which participants relied on the believability and on the reliability of information included in the CEO's updated forecast when making their own forecasts. Recall that findings from psychology on the belief bias predict that investors rely on the believability of information to inform their own beliefs and do not sufficiently consider evidence regarding the reliability or validity of the information. Thus, I expect that even when the updated forecasts have been unreliable in the past, the impact that the favorability of information and the degree of managerial bias have on investor judgments regarding the company's earnings will be mediated by investor judgments regarding the believability of the CEO's explanations in the updated forecasts. That is, investors do not sufficiently utilize the reliability of information in their earnings assessments of the company.

Specifically, there were two questions asked about the press release that the CEO had provided. These questions related to the believability of the CEO's forecast and the believability of the reasons the CEO provided for changing his forecast. (Appendix D includes these questions). I also ask participants a series of additional questions that capture participants' beliefs about the company and management of the company. These questions are designed to test the process through which participants make their judgments concerning the company. In particular, questions regarding the credibility of the $\mathrm{CEO}$ were asked to assess how the lack of credibility influences earnings judgments. (See Appendix E for these process-related questions.) At the end of the case materials, I 
ask several manipulation check questions and also collect demographic data. (See

Appendix F for the manipulation check questions.) 


\section{Chapter 5: Experimental Results}

\subsection{Manipulation Checks}

Recall that I asked several questions to ensure that my two manipulations were successful. To check the favorable versus unfavorable forecast manipulation, I asked participants whether the CEO's press release provided positive or negative information about the firm. Ninety-seven percent of participants responded correctly to this question. Further, the responses were significantly associated with the experimental condition $\left(\chi^{2}=\right.$ $138.46, p<0.01)$, indicating the effectiveness of this manipulation. ${ }^{11}$

To check the level of bias (low bias, high bias / qualitative information, and high bias / quantitative information), I asked two questions—-first, whether the firm's CEO has historically been accurate or inaccurate and, second, whether the participants knew the precise magnitude of the CEO's prior misstatement (whether his forecast had always been different by $\$ 0.05$ from the actual realization of earnings). Ninety-one percent and ninety-five percent of participants responded to the first and second questions, respectively. The responses are also associated with experimental condition $\chi^{2}=133.65$, $p<0.01$ and $\left.\chi^{2}=116.14, p<0.01\right)$, suggesting that my bias manipulation was effective. See table 1 for a summary of these manipulation check results by experimental condition.

Over all manipulation check questions, 124 (82.7\%) of the 150 participants responded correctly to all of the manipulation checks. Thus, the responses to my manipulation check questions indicate that the manipulations were generally very

\footnotetext{
${ }^{11}$ A second question related to the favorable versus unfavorable manipulation asked whether the CEO provided a forecast of $\$ 1.21$ per share or $\$ 1.31$ per share. $99 \%$ of participants responded correctly to this question.
} 
effective. As such, I utilize the results from the full sample to test my hypothesis. I also perform a robustness analysis (reported in section 5.3) where I test the main experimental results on only the sub-sample of participants that responded correctly to all manipulation check questions. The hypothesis test results are similar using this subsample of participants.

\subsection{HyPOTHESIS TESTING}

To test my hypothesis, I employ a $2 \times 3$ between-participants' analysis of variance (ANOVA). I estimate this model separately for the qualitative and quantitative dependent measures and for the likelihood that each investor will buy or sell shares in the company. ${ }^{12}$

Panel A of Table 2 provides the means and standard deviations by condition for participants' responses. Panel B provides the ANOVA results. Panel C details results from the simple-main effects tests. The latter tests provide the most direct evidence for my hypothesis. Figure 3 graphically displays these results.

Recall that my hypothesis indicates an interaction between the favorability of information and the level of bias. In particular, I expect investor' judgments to be more favorable (unfavorable) when managers provide favorable (unfavorable) information under conditions of low bias as compared to high bias (H1a). While I expect investors' judgments to be influenced by less when the bias is high as compared to when the bias is

\footnotetext{
12 My experimental materials included two questions designed to capture a potential investment decision. Not surprisingly the results from these two questions are highly correlated, so the statistical results are similar. Using the second investment decision question does not change any of the inferences made in this dissertation. For that reason, Table 2 includes only the results pertaining to the question asking participants about the likelihood of buying or selling shares in the company rather than the second question asking about the amount of shares that participants would expect to buy or sell.
} 
low, I do not expect that they will always be able to fully unravel the influence of managerial bias (H1b). The only circumstance where I hypothesize that investors will be able to fully unravel the managerial bias is when the precise quantitative value of the bias is known and investors render a compatible quantitative response. With this overall prediction, I expect significant simple main effect tests between the favorable/unfavorable information conditions for each level of bias for all of the dependent variables with one exception—namely, the high bias / quantitative condition where the investor renders a quantitative response (i.e., an EPS estimate) that matches the quantitative nature of the bias information. That is, if the effects of scale-compatibility allow investors to fully unravel, there will be no difference between the favorable and unfavorable condition when the bias is precisely known (i.e. in the high bias / quantitative conditions).

As shown in Table 2, the ANOVAs for both earnings measures ${ }^{13}$ and the investment decision reveal statistically significant interactions (all $p$-values $\leq 0.02$ ), consistent with my predictions (H1a). Turning first to investors' qualitative earnings judgments, recall my hypothesis suggests that although investors will respond to the bias in the information provided by the CEO, their judgments will never show full adjustment for the managerial bias. That is, the qualitative earnings judgments in the favorable and unfavorable conditions will never be statistically equivalent. To test this idea, I examine the simple main effects of favorable/unfavorable information holding constant the level

\footnotetext{
${ }^{13}$ I also collected a price-earnings measure. While the results (untabulated) from this measure show a main effect on the favorability of information $(F=22.84, p=<0.01)$, there is no significant interaction between favorability of information and level of bias $(F=0.19, p=0.83)$.
} 
of bias. As expected based on psychology theory concerning the belief bias, the simple main effects are significant for each bias condition (all $p$-values $\leq 0.01$ ). These qualitative judgments are more positive in the favorable than the unfavorable information conditions whether there is low bias (69.12 versus 39.68), high bias with only qualitative information about the bias (63.28 versus 43.44), or high bias when quantitative information about the bias is known (63.20 versus 51.44). Importantly, even when investors know the precise amount of bias that is in the manager's forecast (i.e. the high bias / quantitative information conditions), investors' qualitative judgments do not sufficiently adjust for the bias. Recall that in this condition, the investors know that the manager's bias has always been $\$ 0.05$ per share and subtracting (adding) this $\$ 0.05$ per share bias from the optimistic (pessimistic) manager's EPS forecast results in an EPS forecast that is equivalent to the consensus analyst forecast previously provided to participants.

Turning next to investors' quantitative earnings judgments - that is, their EPS judgments - I again observe an interaction between bias and favorability of the information from the $\mathrm{CEO}(F=5.05, p=0.01)$. Examining the simple main effect tests shows, as expected, a difference in investors' responses to favorable and unfavorable information for low bias ( $\$ 1.30$ versus $\$ 1.22)$ and high bias when the bias is described in only qualitative terms ( $\$ 1.28$ versus $\$ 1.23$ ) (both $p$-values $<0.01$ ). Surprisingly, I also observe a significant simple main effect for the high bias / quantitative condition. That is, investors' quantitative EPS forecasts differ between the favorable and unfavorable conditions even when the precise quantitative nature of the bias is known ( $\$ 1.28$ versus 
$\$ 1.23, p<0.01)$. Scale-compatibility theory suggests that full unraveling should occur in this situation. Although this result does not support my hypothesis (H1b), it does suggest that the belief bias has a powerful and apparently robust influence on investor judgments. ${ }^{14}$

Finally, I examine the results for two decision questions. Recall that these two questions asked participants how likely they were to buy or sell shares and also how many shares they would buy or sell (assuming they had sufficient funds to buy 10,000 shares). As previously noted, responses to these two questions were highly correlated (correlation coefficient of 0.89 ) and the pattern of results is virtually identical. Accordingly, I limit the discussion here to the question asking participants about the likelihood of their buying or selling shares in the company.

As shown in Panel A of Table 2, once again I find a significant interaction between bias and favorable/unfavorable information using this investment decision as the dependent variable $(F=6.95, p<0.01)$. As with the previous measures, I examine the simple main effects to investigate the degree to which investors are able to adjust for known biases in information provided by the CEO. I find that, holding constant the level of bias and comparing responses to favorable versus unfavorable information, investment decisions significantly differ for the low bias (10.00 versus -9.12$)$ and high bias / qualitative (11.48 versus -9.28$)$ conditions (both $p$-values $<0.01)$. However, in the high

\footnotetext{
14 Initially these results appear consistent with the anchoring and adjustment heuristic (Tversky and Kahneman 1974). However, anchoring and adjustment findings generally relate to situation where individuals anchor on an initial piece of information (usually numerical information). Additionally, the initial piece of information is normally irrelevant to the decision task. In my study, the participants' initial information is the consensus analyst forecast of $\$ 1.26$ earnings per share. If participants were to anchor on this piece of information, this would work against the predictions from the belief bias and the findings in this dissertation.
} 
bias / quantitative condition, the investment decisions were not statistically different between the favorable and unfavorable information conditions $(1.04$ versus $-0.52, p=$ 0.70). These findings seem at odds with the prior results. That is, although I did not observe full unraveling in the quantitative earnings judgments when the scale was compatible, participants' investment decisions in the quantitative conditions did adjust for the known (and quantitative) managerial bias. I will return to this set of results in section 5.5 of this chapter.

In summary, my findings largely support my hypothesis in that investor judgments are unable to fully adjust for known managerial bias. Specifically, a significant interactive effect for each of my main dependent measures demonstrates support for the first part of my hypothesis (H1a). Recall that my hypothesis also suggests that investor judgments will be unable to adjust for known bias except in one specific case (H1b)- namely when investors are asked to make quantitative earnings judgments and they know the precise quantitative effect of the bias (i.e., the high bias / quantitative condition). My findings show that, even in that case, investors are unable to fully adjust for known managerial bias. In this instance my findings are inconsistent with my hypothesis (H1b) but may be indicative of the powerful influence that the belief bias has on individual judgments. In addition, while my hypothesis does not address the investment decision measures, the results from these measures seem to partially contradict my hypothesis. As I said previously, I address this issue in section 5.5. 


\subsection{ROBUSTNESS TEST}

To provide further evidence that those participants that misunderstood the experimental materials do not systematically influence my results, I perform the same analyses as in section 5.2 using only those responses from participants who correctly answered each of the manipulation check questions. As explained previously in section 5.1 , the majority of participants $(82.7 \%)$ responded correctly to each of the manipulation check questions across all experimental conditions.

Panel A of Table 3 provides the descriptive statistics and analysis for the two judgment variables and the decision variable. Of particular note is the consistency of the results in this sample as compared to the entire population. Panel B shows a significant interaction between the favorability of earnings and the level of bias for the three dependent variables (qualitative earnings measure, quantitative earnings measure, and likely to buy or sell shares measure). In addition, the simple main effects testing for the qualitative and quantitative earnings measures in Panel C shows significant differences between the unfavorable and favorable forecast conditions across all levels of bias (all $p$ values $<0.01)$. Finally, for the dependent measures testing how likely investors are to buy or sell shares in the company the results remain consistent with those found on the entire sample and explained previously in section 5.2. That is, simple main effects testing reveal a significant difference between the unfavorable and favorable conditions in the low bias / qualitative and high bias / qualitative conditions (both $p$-values $<0.01$ ), but there is no significant difference between the unfavorable and favorable conditions in 
the high bias / quantitative condition (3.14 versus $-0.05, p=0.46)$. In sum, these analyses suggest the robustness of the findings.

\subsection{Path Analysis}

Recall that my predictions are based on the idea that investors are likely to automatically believe information presented by firm managers, even after other information suggests that it is biased. These investors are, in most instances, unable to fully unravel the effects of the bias. To test that it is, in fact, the believability of information causing my results, I estimate a path model using structural equation modeling techniques. Such testing allows me to causally link my manipulations and dependent measure results to the notion of believability. Further, path analysis allows me to simultaneously test both the direct and indirect effects within the model. ${ }^{15}$ Figure 4 shows the general form of the model that I am testing. Note that my model specification includes both the main effects associated with the independent variables (i.e. the favorability the information and the level of bias) in addition to the interaction of these two variables. Given that I am primarily interested in the interaction term (and the ANOVA results reveal a significant interaction), for simplicity I only show the interaction term in my diagram.

In the model, there are two potential indirect pathways from the interaction of information favorability and the level of bias to earnings judgments. The belief bias would suggest that earnings judgments are primarily influenced via the believability of

\footnotetext{
15 Path analysis is a widely accepted method of modeling and testing the effects that manipulated variables have on dependent variables (see Towry 2003; and Koonce, McAnally, and Mercer 2005 for examples of similar testing in accounting research).
} 
manager explanations (i.e. the content of the message) and less so by the credibility of the manager (i.e. a judgment concerning the veracity of the message). Although I include both of these pathways in my model, I expect, based on the belief bias, that only the indirect pathway through the believability of manager explanations will be statistically significant. To conclude that investors are unable to fully adjust their earnings judgments because of the believability of manager explanations, I must observe a significant indirect effect from the interaction of my independent variables (favorability $\times$ bias) to the earnings judgment via link 1 and link 2 (as shown in Figure 4). A significant indirect link from favorability $\times$ bias to the earnings judgment via link 4 and link 5 would indicate that the credibility of the manager mediates, at least in part, the relationship observed between those variables. In addition, a significant result for link 3 would represent a direct effect from favorability $\times$ bias to the earnings judgment. Observing a significant direct effect (link 3) does not necessarily contradict the belief bias; however, it suggests there may be factors in addition to believability of manager explanations that impact investor judgments.

To measure the believability of manager explanations, I asked participants to indicate the degree to which the reasons provided by the CEO in the company's press release were believable. The 101-point response scale had endpoints of 0 (not at all believable) and 100 (very believable). ${ }^{16}$ To appropriately analyze this response, I reverse scored the believability responses in the unfavorable conditions. For example, a strong

\footnotetext{
16 I acknowledge that this measure relies on participants having self-insight regarding their beliefs and then accurately reporting those beliefs. Arguably, both of these tasks may be difficult as beliefs are difficult to quantify and subconscious beliefs may exist that are, by their very nature, difficult to measure or report (Nisbett and Wilson 1977). To the extent that these factors are at work, they work against my finding significant results in this path model as measurement noise would be increased.
} 
belief in the unfavorable CEO information condition (i.e., a believability measure recorded as 80 ) is coded with a negative sign (i.e., -80). This reverse scoring is necessary to capture the hypothesized correlation between stronger believability in management's information (whether it is favorable or unfavorable information) and more extreme (favorable or unfavorable) earnings judgments. ${ }^{17}$

To construct a measure of the credibility of the manager, I aggregate participant responses from two questions. Participants assess both the trustworthiness and competence of the $\mathrm{CEO}$ on a scale from 0 to 100 . The endpoints from the trustworthiness (competence) scale were not at all trustworthy (competent) and very trustworthy (competent). Participant ratings from these two questions are equally weighted in calculating the credibility measure, consistent with prior research (Mercer 2005). ${ }^{18}$ Again, for the credibility measure, I reverse score participant responses in my analyses. That is, when measures are taken from the unfavorable information conditions, the responses are coded with a negative sign, just as I had done with believability measure.

Results for these believability and credibility measures are tabulated in Panel A of Table 4, with the corresponding statistics shown in Panel B.

I estimate the model described previously two times - once for the qualitative earnings judgment and once for the quantitative earnings judgment. These models and

\footnotetext{
${ }^{17}$ Recall that I also asked participants to rate the believability of the CEO's earnings per share forecast. This measure is not expected to mediate my findings and untabulated analyses confirm this expectation. I expect that even though participants recognize the lack of reliability in specific earnings per share forecast (and thus reduce the degree to which they believe the specific forecast) they may still be influenced by the believability of the explanations provided for that forecast, despite the source. Indeed I find that the believability of the explanations and not the specific forecast mediate investors' earnings judgments. ${ }^{18}$ I also performed the analysis using only trustworthiness (rather than credibility) in the model. I find similar results using this variable. Specifically, trustworthiness does not significantly mediate the influence that my interaction variable has on investor judgments.
} 
their results are presented in Figure 5. Turning first to the qualitative earnings measure, I begin by testing the fit of the model. I find an acceptable model fit as the chi-square test of model fit demonstrates a $p$-value above $0.05\left(\chi^{2}=0.82, p=0.36\right)$ and the comparative fit index (CFI) of the model is 1.00 , above the accepted cutoff value of 0.95 (Hu and Bentler 1999).

Results for the indirect effects of the favorability $\times$ bias interaction to the qualitative earnings judgment via the believability of manager explanations are consistent with predictions based on the belief bias (links 1 and 2 together are significant at $p=$ 0.06). This finding is consistent with my theory, suggesting that the believability of managerial explanations plays a significant role in investor's qualitative judgments. Also consistent with my theory, the indirect effect via the credibility of the manager is not significant (links 4 and 5 together are insignificant at $p=0.31$ ). Finally, the favorability $\times$ bias interaction has a significant direct effect on the qualitative earnings judgments $(p=$ 0.02 , link 3), suggesting that additional processes may also mediate this pathway. ${ }^{19}$

Turning to the model using the quantitative earnings measures, I again find that the chi-square test of model fit indicates an acceptable fit $\left(\chi^{2}=0.82, p=0.36\right)$. The comparative fit index (CFI) of the model is also at an acceptable level of 1.00. I find that the pattern of results for the quantitative earning judgments is similar to, albeit somewhat weaker than, the qualitative judgment results just discussed. The indirect effects from favorability $\times$ bias to the quantitative earnings judgment is statistically weaker (Links 1

\footnotetext{
${ }^{19}$ I collect participants' self-reported ratings for other factors that are known to influence investor judgments. These variables include the risk associated with the company and the ease of forecasting future earnings for the company. Based on the theory developed in this paper, I do not expect to find (and I do not find) that any of these variables significantly mediate the relationship between my independent variables and investor judgments.
} 
and 2 together have a $p=0.14$ as compared to $p=0.06$ using qualitative earnings judgments). The indirect effect via the credibility of the manager is clearly not significant (Links 4 and 5 together, $p=0.62$ ).

In summary, my findings using path analysis are largely consistent with the predictions based on the belief bias. Investors' inability to fully adjust for known managerial bias appears to be caused by the believability of the information provided. Investors do not adequately adjust their judgments for the unreliability in information even when the factors causing that unreliability (e.g., managerial biases) are fully known.

\subsection{Possible Reconciliation OF Results For JUdGMENTS AND INVESTMENT DECISIONS}

Recall that my results show that unraveling does not occur even in the situation where I hypothesized that it would — namely, the high-bias / quantitative conditions where the participants' responses were in a quantitative format. In this condition, the participants knew the precise amount of the bias in the CEO's press release (i.e. $\$ 0.05$ different from what the actual earnings realization would be). Even in this condition, I observe that quantitative judgments in the favorable information condition are more favorable than those in the unfavorable condition. Although this result is inconsistent with my predictions, I did observe behavior that appears consistent with complete unraveling when examining the investment decision results. As shown in Figure 3, participants' decisions regarding investing in shares or divesting their current shares are statistically identical and do not depend on the favorableness of the information (1.04 versus $-0.52 ; F=0.15, p=0.70)$. 
This finding is unexpected but perhaps not necessarily inconsistent, albeit made on an ex post basis, with prior decision-making research. Specifically, research has shown that when presented with a choice individuals anticipate the regret that they may have when making the choice and they try to eliminate or minimize that potential regret (Connolly and Zeelendberg 2002). This research on regret aversion has been demonstrated to influence the choices people make in a variety of decision situations (e.g. Larrick and Boles 1995, Seta, et al. 2001). Importantly, regret aversion has also been shown to influence the entire decision making process (Reb 2008). As decision makers anticipate an increasing potential for regret with their choice, they undertake an increasingly careful analysis of their decision. This increase can cause a search for additional facts and a more in depth analysis of the known facts. In doing so, decisionmakers may reconsider their prior held beliefs and judgments.

Recall that in my experiment, participants were asked to make the qualitative and quantitative judgments prior to being asked to make investment decisions. Therefore, when faced with an investment decision, investors could have considered the degree to which they may regret that potential decision. For example, they may have thought about regret either in overinvestment in a company that performs more poorly than expected or underinvestment in a company that subsequently performs better than expected. In the face of such potential regret, it is possible that participants in my experiment, once faced with the decision question, returned (either physically or in their memory) to the 
experimental materials to reconsider the facts pertaining to the company. ${ }^{20}$ In doing so, participants in the high bias / quantitative information conditions, found a precise quantitative level of bias that they could use to reformulate their prior expectations and judgments. In so doing, participants in these two conditions could have been more likely to render decisions that were inconsistent with their former judgments. My results detail that participants in the high bias / quantitative information conditions did make decisions that were inconsistent with their pre-decisional judgments. That is, in the high bias / quantitative conditions participants with favorable disclosures made statistically different judgments than participants with unfavorable disclosures but the investment decisions did not differ between these two groups.

Given this ex post possibility of why full unraveling occurred for the quantitative bias participants in their investment decisions but not their judgments, the natural next question is why didn't similar behavior occur in those participants faced with high bias qualitative disclosures. There, even if participants faced with making an investment decision (and faced with potential regret for a poor decision) revisited the prior information about the bias in the case materials, they could not unravel the bias. Thus, while they may have tried to avoid regret and re-process the available information, they were unable to ascertain the precise amount of adjustment required and continued to rely on the manager's biased information. Hence, both their judgments and decisions

\footnotetext{
20 The experimental materials were not so exhaustive as to overwhelm the participants and, thus, they likely could remember the specific facts included in the materials. Nevertheless, except when responding to the process-related and manipulation check questions, participants completing the experiment were allowed to refer to the background information in the materials as necessary.
} 
exhibited the effects of the initial erroneous information. Whether this ex post possibility is valid is certainly subject to further research. 


\section{Chapter 6: Conclusions}

A long-standing assumption in both economics and accounting is that investors will fully adjust for known biases in reported information. My study challenges this assumption. I show that investors underweight the impact that managerial bias has on information communicated and are largely unable to correct their judgments for this innate tendency. Relaxing the assumption that investors will fully adjust for managerial bias, I hope to assist researchers in developing improved predictive models and providing additional explanations for empirical findings. Understanding how investors respond to managerial communications also has important implications for regulators and investors. One of primary roles of regulators is to ensure useful information is provided to market participants. My study serves to emphasize the importance of managers providing reliable information and cautions against the tendency of investors to underestimate or ignore important biases in financial reporting settings.

The belief bias does have a significant influence on investor judgments. I show that this tendency is strong and robust, and overwhelms the potentially debiasing impact of scale compatibility. My study demonstrates that even in cases where one would expect investors to be the least susceptible to the belief bias (i.e. the managerial bias is known with precision and the response scale matches the bias scale), investors are not able to fully unravel for the effects of the bias in their earnings judgments.

Finally, my study adds to the literature suggesting that investors are unable to fully unravel managerial bias. While acknowledging that prior studies offer some plausible reasons for investors' inability to fully adjust in many situations, I show that 
even when the typical constraints to investors unraveling abilities are lifted (e.g. investors have all information about the firm and managerial biases, they have sufficient time and resources, and there are no transaction costs), investors will still fail to fully adjust for managerial bias.

My study raises a number of potential avenues for future research. First, future research could help bring clarity to the noted discrepancy between investor judgments and investment decisions. I posited, albeit on an ex post basis, that regret aversion was instrumental in understanding why those participants who were provided quantitative information about the managers' bias were able to unravel for the bias in their decisions (but not their judgments). One possible way to test this ex post idea is very simplenamely, reverse the order of the decisions and judgments. In my study, I asked participants to make judgments prior to decisions. Given that regret aversion only comes into play for decisions, it is possible that full unraveling in judgments may occur only once a decision has been made. While this possibility deserves additional research, it would also have to contend with other possible contaminating factors that arise with such a research design (e.g., motivated reasoning concerns once a decision has been made (e.g., Kunda 1990)).

Second, future research could explore the temporal aspects of unraveling. That is, while investors decisions may, under certain circumstances, demonstrate unraveling for managerial bias, does this unraveling "stick?" In a recent marketing study, Chan and Sengupta (2010) find that consumers are able to adjust for an advertiser's obvious intentions to flatter them when asked about the advertiser's intent (i.e. persuade 
customers to buy products) at the same time that the advertisement is viewed. However, after several days have passed, the consumers' purchasing behavior increases as a result of the biased advertisement. The immediate, explicit attitude measure is discounted for the known flattery, but the subsequent behavioral intentions still reflect the underlying bias, consistent with the belief bias. Although I tested for unraveling on an "immediate" basis, future research could explore whether any unraveling "unravels itself" as time passes. In sum, there are many possible directions for future research on the important topic of managerial bias. 


\section{Table 1: Manipulation Check Results}

Percentage of participants who correctly responded to manipulation check questions by condition

\begin{tabular}{|c|c|c|c|c|c|c|}
\hline & \multicolumn{2}{|c|}{$\begin{array}{c}\text { Favorable / Unfavorable } \\
\text { Manipulation }\end{array}$} & \multicolumn{2}{|c|}{$\begin{array}{c}\text { High Bias / Low Bias } \\
\text { Manipulation }\end{array}$} & \multicolumn{2}{|c|}{$\begin{array}{c}\text { Qualitative / Quantitative } \\
\text { Manipulation }\end{array}$} \\
\hline & $\begin{array}{c}\text { Favorable } \\
\text { Forecast }\end{array}$ & $\begin{array}{c}\text { Unfavorable } \\
\text { Forecast }\end{array}$ & $\begin{array}{c}\text { Favorable } \\
\text { Forecast }\end{array}$ & $\begin{array}{c}\text { Unfavorable } \\
\text { Forecast }\end{array}$ & $\begin{array}{c}\text { Favorable } \\
\text { Forecast }\end{array}$ & $\begin{array}{c}\text { Unfavorable } \\
\text { Forecast }\end{array}$ \\
\hline $\begin{array}{l}\text { Low Bias / } \\
\text { Qualitative }\end{array}$ & $\begin{array}{l}100 \% \\
(\mathrm{n}=25)\end{array}$ & $\begin{array}{l}100 \% \\
(\mathrm{n}=25)\end{array}$ & $\begin{array}{l}88 \% \\
(\mathrm{n}=25)\end{array}$ & $\begin{array}{c}80 \% \\
(\mathrm{n}=25)\end{array}$ & $\begin{array}{l}100 \% \\
(\mathrm{n}=25)\end{array}$ & $\begin{array}{l}100 \% \\
(\mathrm{n}=25)\end{array}$ \\
\hline $\begin{array}{l}\text { High Bias / } \\
\text { Qualitative }\end{array}$ & $\begin{array}{l}100 \% \\
(\mathrm{n}=25)\end{array}$ & $\begin{array}{l}92 \% \\
(\mathrm{n}=25)\end{array}$ & $\begin{array}{l}96 \% \\
(n=25)\end{array}$ & $\begin{array}{l}96 \% \\
(n=25)\end{array}$ & $\begin{array}{l}92 \% \\
(\mathrm{n}=25)\end{array}$ & $\begin{array}{l}100 \% \\
(n=25)\end{array}$ \\
\hline $\begin{array}{l}\text { High Bias / } \\
\text { Quantitative }\end{array}$ & $\begin{array}{l}100 \% \\
(\mathrm{n}=25)\end{array}$ & $\begin{array}{l}96 \% \\
(\mathrm{n}=25)\end{array}$ & $\begin{array}{l}88 \% \\
(\mathrm{n}=25)\end{array}$ & $\begin{array}{l}100 \% \\
(\mathrm{n}=25)\end{array}$ & $\begin{array}{l}88 \% \\
(\mathrm{n}=25)\end{array}$ & $\begin{array}{l}88 \% \\
(\mathrm{n}=25)\end{array}$ \\
\hline
\end{tabular}

Table 1 displays the percentage of participants, by condition, that responded correctly to three manipulation check questions. The first question tested the favorable / unfavorable press release manipulation by asking participants whether the press release suggested a positive or negative outlook for the company. The second question tested the high bias / low bias manipulation by asking participants whether the CEO had historically issued accurate or inaccurate forecasts. The third question verified the qualitative / quantitative manipulation by asking participants whether they were provided with the dollar magnitude difference between the CEO's prior forecasts and actual earnings realizations. 
Table 2: Main Experimental Results

PANEL A: Descriptive Statistics-Means (Standard Deviations)

\begin{tabular}{ccccccc}
\hline & \multicolumn{2}{c}{$\begin{array}{c}\text { Qualitative Earnings } \\
\text { Measure }\end{array}$} & \multicolumn{2}{c}{$\begin{array}{c}\text { Quantitative Earnings } \\
\text { Measure }\end{array}$} & \multicolumn{2}{c}{$\begin{array}{c}\text { Likely to Buy or } \\
\text { Sell Shares }\end{array}$} \\
\cline { 2 - 7 } & $\begin{array}{c}\text { Favorable } \\
\text { Forecast }\end{array}$ & $\begin{array}{c}\text { Unfavorable } \\
\text { Forecast }\end{array}$ & $\begin{array}{c}\text { Favorable } \\
\text { Forecast }\end{array}$ & $\begin{array}{c}\text { Unfavorable } \\
\text { Forecast }\end{array}$ & $\begin{array}{c}\text { Favorable } \\
\text { Forecast }\end{array}$ & $\begin{array}{c}\text { Unfavorable } \\
\text { Forecast }\end{array}$ \\
\cline { 2 - 7 } Low Bias / & 69.12 & 39.68 & 1.30 & 1.22 & 10.00 & -9.12 \\
Qualitative & $(13.47)$ & $(17.17)$ & $(0.02)$ & $(0.02)$ & $(14.86)$ & $(16.94)$ \\
& $(\mathrm{n}=25)$ & $(\mathrm{n}=25)$ & $(\mathrm{n}=25)$ & $(\mathrm{n}=25)$ & $(\mathrm{n}=25)$ & $(\mathrm{n}=25)$ \\
High Bias / & & & & & & \\
Qualitative & $(16.76)$ & $(12.13)$ & $(0.04)$ & $(0.03)$ & $(11.17)$ & $(15.17)$ \\
& $(\mathrm{n}=25)$ & $(\mathrm{n}=25)$ & $(\mathrm{n}=25)$ & $(\mathrm{n}=25)$ & $(\mathrm{n}=25)$ & $(\mathrm{n}=25)$ \\
High Bias / & & & & & & \\
Quantitative & $(16.71)$ & $(15.24)$ & $(0.03)$ & $(0.04)$ & $(14.77)$ & $(11.92)$ \\
& $(\mathrm{n}=25)$ & $(\mathrm{n}=25)$ & $(\mathrm{n}=25)$ & $(\mathrm{n}=25)$ & $(\mathrm{n}=25)$ & $(\mathrm{n}=25)$ \\
\hline
\end{tabular}

PANEL B: Main ANOVA Results

\begin{tabular}{|l|c|c|c|c|c|c|c|c|c|}
\hline Source & \multicolumn{4}{|c|}{$\begin{array}{c}\text { Qualitative Earnings } \\
\text { Measure }\end{array}$} & \multicolumn{2}{c|}{$\begin{array}{c}\text { Quantitative Earnings } \\
\text { Measure }\end{array}$} & \multicolumn{3}{c|}{$\begin{array}{c}\text { Likely to Buy or } \\
\text { Sell Shares }\end{array}$} \\
\hline & $\boldsymbol{d f}$ & Statistic & $\begin{array}{c}\text { Two-tailed } \\
\boldsymbol{p} \text {-value }\end{array}$ & $\boldsymbol{d f}$ & Statistic & $\begin{array}{c}\text { Two-tailed } \\
\boldsymbol{p} \text {-value }\end{array}$ & $\boldsymbol{d} \boldsymbol{d f}$ & Statistic & $\begin{array}{c}\text { Two-tailed } \\
\boldsymbol{p} \text {-value }\end{array}$ \\
\hline Favorability of Forecast & 1 & $F=65.79$ & $<0.01$ & 1 & $F=155.4$ & $<0.01$ & 1 & $F=35.11$ & $<0.01$ \\
\hline Level of Bias & 2 & $F=0.89$ & 0.41 & 2 & $F=0.45$ & 0.64 & 2 & $F=0.05$ & 0.95 \\
\hline Favorability $\times$ Bias & 2 & $F=4.15$ & 0.02 & 2 & $F=5.05$ & 0.01 & 2 & $F=6.95$ & $<0.01$ \\
\hline
\end{tabular}


PANEL C: Planned Contrast and Simple Main Effect Tests

\begin{tabular}{|c|c|c|c|c|c|c|c|c|c|}
\hline & \multicolumn{3}{|c|}{$\begin{array}{c}\text { Qualitative Earnings } \\
\text { Measure }\end{array}$} & \multicolumn{3}{|c|}{$\begin{array}{c}\text { Quantitative Earnings } \\
\text { Measure }\end{array}$} & \multicolumn{3}{|c|}{$\begin{array}{l}\text { Likely to Buy or } \\
\text { Sell Shares }\end{array}$} \\
\hline & $d f$ & Statistic & $\begin{array}{c}\text { Two-tailed } \\
p \text {-value }\end{array}$ & $d f$ & Statistic & $\begin{array}{c}\text { Two-tailed } \\
p \text {-value }\end{array}$ & $d f$ & Statistic & $\begin{array}{c}\text { Two-tailed } \\
p \text {-value }\end{array}$ \\
\hline \multicolumn{10}{|c|}{ Comparing Unfavorable versus Favorable Forecast: } \\
\hline Low Bias / Qualitative & 1 & $F=45.91$ & $<0.01$ & 1 & $F=94.36$ & $<0.01$ & 1 & $F=22.42$ & $<0.01$ \\
\hline High Bias / Qualitative & 1 & $F=20.85$ & $<0.01$ & 1 & $F=42.04$ & $<0.01$ & 1 & $F=26.43$ & $<0.01$ \\
\hline High Bias / Quantitative & 1 & $F=7.33$ & 0.01 & 1 & $F=29.07$ & $<0.01$ & 1 & $F=0.15$ & 0.70 \\
\hline \multicolumn{10}{|c|}{ Comparing Across All Levels of Bias: } \\
\hline Favorable Forecast & 2 & $F=1.22$ & 0.30 & 2 & $F=4.16$ & 0.02 & 2 & $F=3.91$ & 0.02 \\
\hline Unfavorable Forecast & 2 & $F=3.82$ & 0.02 & 2 & $F=1.35$ & 0.26 & 2 & $F=3.08$ & 0.05 \\
\hline
\end{tabular}

Table 2 shows descriptive statistics and analysis for the three dependent measure questions discussed in my results. In my $2 \times 3$ experiment, I manipulate the information favorability of a company's press release (favorable or unfavorable) and level of bias for the company's CEO (low bias, high bias / qualitative, and high bias / quantitative). The qualitative earnings question asks participants to rate the favorability of the company's current net income. The quantitative earnings question asks participants to provide an earnings per share estimate for the company's current year. Lastly, the third question asks participants to indicate how likely they would be to buy or sell shares in the company based on the information provided. 
Table 3: Robustness Results

PANEL A: Descriptive Statistics-Means (Standard Deviations)

\begin{tabular}{ccccccc}
\hline & \multicolumn{2}{c}{$\begin{array}{c}\text { Qualitative Earnings } \\
\text { Measure }\end{array}$} & \multicolumn{2}{c}{$\begin{array}{c}\text { Quantitative Earnings } \\
\text { Measure }\end{array}$} & \multicolumn{2}{c}{$\begin{array}{c}\text { Likely to Buy or } \\
\text { Sell Shares }\end{array}$} \\
\cline { 2 - 7 } & $\begin{array}{c}\text { Favorable } \\
\text { Forecast }\end{array}$ & $\begin{array}{c}\text { Unfavorable } \\
\text { Forecast }\end{array}$ & $\begin{array}{c}\text { Favorable } \\
\text { Forecast }\end{array}$ & $\begin{array}{c}\text { Unfavorable } \\
\text { Forecast }\end{array}$ & $\begin{array}{c}\text { Favorable } \\
\text { Forecast }\end{array}$ & $\begin{array}{c}\text { Unfavorable } \\
\text { Forecast }\end{array}$ \\
\cline { 2 - 8 } Low Bias / & 69.32 & 36.06 & 1.30 & 1.22 & 9.52 & -10.22 \\
Qualitative & $(13.32)$ & $(12.95)$ & $(0.02)$ & $(0.02)$ & $(15.81)$ & $(15.86)$ \\
$(\mathrm{n}=21)$ & $(\mathrm{n}=18)$ & $(\mathrm{n}=21)$ & $(\mathrm{n}=18)$ & $(\mathrm{n}=21)$ & $(\mathrm{n}=18)$ \\
& & & & & & \\
High Bias / & 63.05 & 42.55 & 1.28 & 1.22 & 11.68 & -9.64 \\
Qualitative & $(17.29)$ & $(9.72)$ & $(0.04)$ & $(0.03)$ & $(11.52)$ & $(15.48)$ \\
& $(\mathrm{n}=22)$ & $(\mathrm{n}=22)$ & $(\mathrm{n}=22)$ & $(\mathrm{n}=22)$ & $(\mathrm{n}=22)$ & $(\mathrm{n}=22)$ \\
High Bias / & 62.86 & 51.25 & 1.27 & 1.23 & 3.14 & -0.05 \\
Quantitative & $(17.29)$ & $(16.61)$ & $(0.03)$ & $(0.04)$ & $(11.52)$ & $(12.95)$ \\
& $(\mathrm{n}=21)$ & $(\mathrm{n}=20)$ & $(\mathrm{n}=21)$ & $(\mathrm{n}=20)$ & $(\mathrm{n}=21)$ & $(\mathrm{n}=20)$ \\
& & & & & & \\
\hline
\end{tabular}

PANEL B: Main ANOVA Results

\begin{tabular}{|l|c|c|c|c|c|c|c|c|c|}
\hline Source & \multicolumn{3}{|c|}{$\begin{array}{c}\text { Qualitative Earnings } \\
\text { Measure }\end{array}$} & \multicolumn{2}{c|}{$\begin{array}{c}\text { Quantitative Earnings } \\
\text { Measure }\end{array}$} & \multicolumn{3}{c|}{$\begin{array}{c}\text { Likely to Buy or } \\
\text { Sell Shares }\end{array}$} \\
\hline & $\boldsymbol{d} \boldsymbol{f}$ & Statistic & $\begin{array}{c}\text { Two-tailed } \\
\boldsymbol{p} \text {-value }\end{array}$ & $\boldsymbol{d} \boldsymbol{f}$ & Statistic & $\begin{array}{c}\text { Two-tailed } \\
\boldsymbol{p} \text {-value }\end{array}$ & $\boldsymbol{d} \boldsymbol{d}$ & Statistic & $\begin{array}{c}\text { Two-tailed } \\
\boldsymbol{p} \text {-value }\end{array}$ \\
\hline Favorability of Forecast & 1 & $F=66.26$ & $<0.01$ & 1 & $F=119.4$ & $<0.01$ & 1 & $F=35.85$ & $<0.01$ \\
\hline Level of Bias & 2 & $F=0.89$ & 0.32 & 2 & $F=0.53$ & 0.59 & 2 & $F=0.20$ & 0.85 \\
\hline Favorability $\times$ Bias & 2 & $F=5.33$ & 0.01 & 2 & $F=4.44$ & 0.01 & 2 & $F=5.41$ & 0.01 \\
\hline
\end{tabular}


PANEL C: Planned Contrast and Simple Main Effect Tests

\begin{tabular}{|c|c|c|c|c|c|c|c|c|c|}
\hline & \multicolumn{3}{|c|}{$\begin{array}{c}\text { Qualitative Earnings } \\
\text { Measure }\end{array}$} & \multicolumn{3}{|c|}{$\begin{array}{c}\text { Quantitative Earnings } \\
\text { Measure }\end{array}$} & \multicolumn{3}{|c|}{$\begin{array}{l}\text { Likely to Buy or } \\
\text { Sell Shares }\end{array}$} \\
\hline & $d f$ & Statistic & $\begin{array}{c}\text { Two-tailed } \\
p \text {-value }\end{array}$ & $d f$ & Statistic & $\begin{array}{c}\text { Two-tailed } \\
p \text {-value }\end{array}$ & df & Statistic & $\begin{array}{c}\text { Two-tailed } \\
p \text {-value }\end{array}$ \\
\hline \multicolumn{10}{|c|}{ Comparing Unfavorable versus Favorable Forecast: } \\
\hline Low Bias / Qualitative & 1 & $F=48.53$ & $<0.01$ & 1 & $F=71.25$ & $<0.01$ & 1 & $F=19.61$ & $<0.01$ \\
\hline High Bias / Qualitative & 1 & $F=20.90$ & $<0.01$ & 1 & $F=34.62$ & $<0.01$ & 1 & $F=25.95$ & $<0.01$ \\
\hline High Bias / Quantitative & 1 & $F=6.24$ & 0.01 & 1 & $F=20.55$ & $<0.01$ & 1 & $F=0.54$ & 0.46 \\
\hline \multicolumn{10}{|c|}{ Comparing Across All Levels of Bias: } \\
\hline Favorable Forecast & 2 & $F=1.30$ & 0.28 & 2 & $F=4.20$ & 0.02 & 2 & $F=2.81$ & 0.12 \\
\hline Unfavorable Forecast & 2 & $F=5.02$ & $<0.01$ & 2 & $F=0.96$ & 0.39 & 2 & $F=3.37$ & 0.04 \\
\hline
\end{tabular}

Table 3 shows descriptive statistics and analysis for the three dependent measure questions discussed in the robustness section of my results. The above statistics include the results for only those participants that correctly responded to each of the manipulation check questions. 26 of the 150 participants did not correctly respond to each of the manipulation check questions and have thus been excluded from the analysis in the above table. In my $2 \times 3$ experiment, I manipulate the information favorability of a company's press release (favorable or unfavorable) and level of bias for the company's CEO (low bias, high bias / qualitative, and high bias / quantitative). The qualitative earnings question asks participants to rate the favorability of the company's current net income. The quantitative earnings question asks participants to provide an earnings per share estimate for the company's current year. Lastly, the third question asks participants to indicate how likely they would be to buy or sell shares in the company based on the information provided. 
Table 4: Believability of Manager Explanations and Credibility of Manager Measures

PANEL A: Descriptive Statistics-Means (Standard Deviations)

\begin{tabular}{ccccc}
\hline & $\begin{array}{c}\text { Believability of Manager } \\
\text { Explanations }\end{array}$ & \multicolumn{2}{c}{$\begin{array}{c}\text { Credibility of } \\
\text { Manager }\end{array}$} \\
\cline { 2 - 5 } & $\begin{array}{c}\text { Favorable } \\
\text { Forecast }\end{array}$ & $\begin{array}{c}\text { Unfavorable } \\
\text { Forecast }\end{array}$ & $\begin{array}{c}\text { Favorable } \\
\text { Forecast }\end{array}$ & $\begin{array}{c}\text { Unfavorable } \\
\text { Forecast }\end{array}$ \\
\cline { 2 - 5 } Low Bias / & 65.13 & -66.48 & 64.68 & -68.04 \\
Qualitative & $(17.31)$ & $(17.17)$ & $(13.61)$ & $(14.26)$ \\
& $(\mathrm{n}=24)$ & $(\mathrm{n}=25)$ & $(\mathrm{n}=25)$ & $(\mathrm{n}=25)$ \\
& & & & \\
High Bias / & 58.52 & -66.20 & 49.22 & -46.84 \\
Qualitative & $(17.12)$ & $(16.56)$ & $(16.74)$ & $(12.11)$ \\
& $(\mathrm{n}=25)$ & $(\mathrm{n}=25)$ & $(\mathrm{n}=25)$ & $(\mathrm{n}=25)$ \\
& & & & \\
High Bias / & 45.24 & -56.68 & 48.64 & -47.67 \\
Quantitative & $(22.26)$ & $(23.71)$ & $(14.88)$ & $(15.73)$ \\
& $(\mathrm{n}=25)$ & $(\mathrm{n}=25)$ & $(\mathrm{n}=25)$ & $(\mathrm{n}=24)$ \\
\hline
\end{tabular}

PANEL B: ANOVA Results

\begin{tabular}{|c|c|c|c|c|c|c|}
\hline Source & \multicolumn{3}{|c|}{$\begin{array}{c}\text { Believability of Manager } \\
\text { Explanations }\end{array}$} & \multicolumn{4}{c|}{$\begin{array}{c}\text { Credibility of } \\
\text { Manager }\end{array}$} \\
\hline & $\boldsymbol{d f}$ & Statistic & $\begin{array}{c}\text { Two-tailed } \\
\boldsymbol{p} \text {-value }\end{array}$ & $\boldsymbol{d f}$ & Statistic & $\begin{array}{c}\text { Two-tailed } \\
\boldsymbol{p} \text {-value }\end{array}$ \\
\hline Favorability of Forecast & 1 & $F=1433$ & $<0.01$ & 1 & $F=2045$ & $<0.01$ \\
\hline Level of Bias & 2 & $F=0.87$ & 0.42 & 2 & $F=0.52$ & 0.59 \\
\hline Favorability $\times$ Bias & 2 & $F=8.10$ & $<0.01$ & 2 & $F=25.92$ & $<0.01$ \\
\hline
\end{tabular}


Table 4 shows descriptive statistics and analysis for the believability of manager explanations and the credibility of manager measures discussed in my results and analyzed in my structural equation model. The believability question asks participants to rate the believability of the CEO's explanations provided in the company's press release on a scale from 0 (not at all believable) to 100 (very believable). The credibility measure is an aggregate measure from two questions in the experimental materials. Participants assess the trustworthiness and competence of the CEO on a scale from 0 (not at all

trustworthy/competent) to 100 (very trustworthy/competent). These two scores are equally weighted in calculating the credibility score, consistent with prior research in accounting (Mercer 2005). I reverse score both of these measures in order to use the ANOVA results to demonstrate a pattern of results consistent with the earnings judgments as recorded in table 2. 
Figure 1: Situational factors influencing information reliability

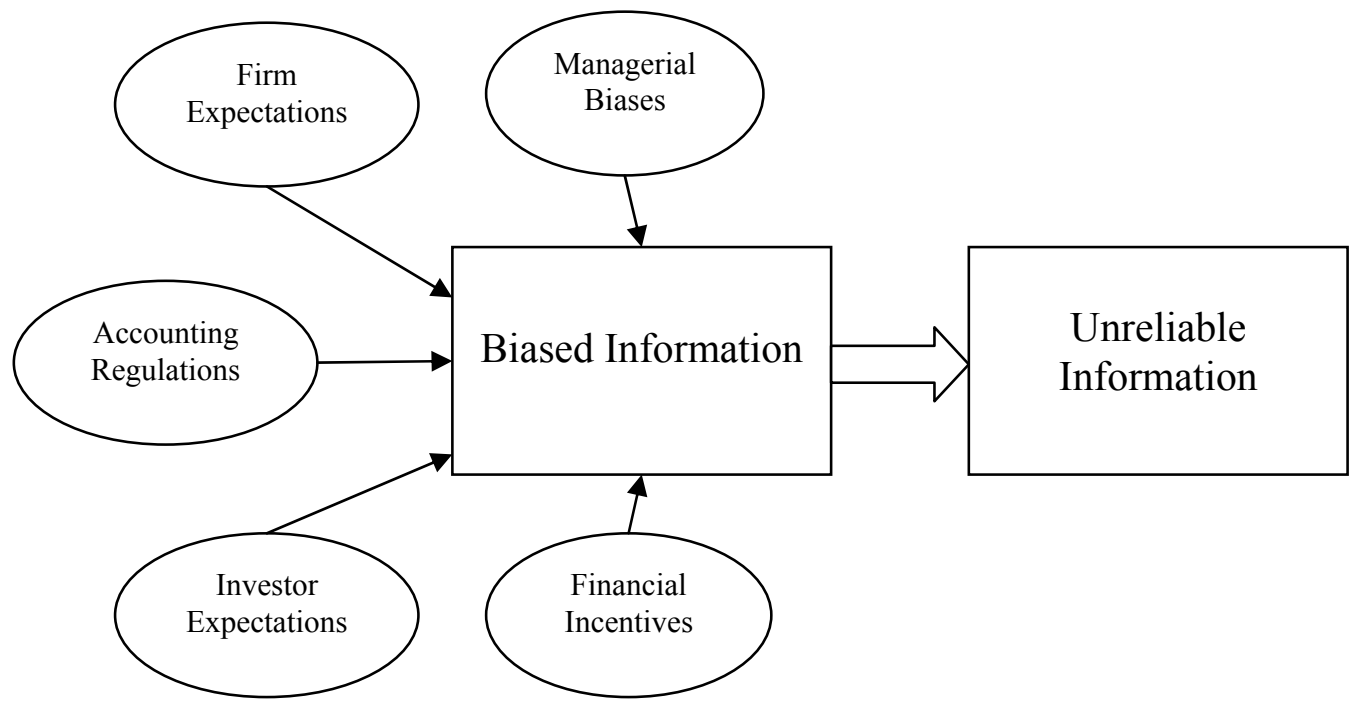

In a financial reporting context, there are many situations that can influence the reliability of information disclosed. These situations, examples of which are identified by ovals in the figure above, can result in biased information being presented in managerial communications. Biased information decreases in the reliability of information and reduces the usefulness of managerial communications for investors. 
Figure 2: Predicted results - investors' qualitative earnings judgments (favorability of earnings) and quantitative earnings judgments (EPS estimates) regarding the current year's earnings by experimental condition

I. Qualitative Earnings Judgments

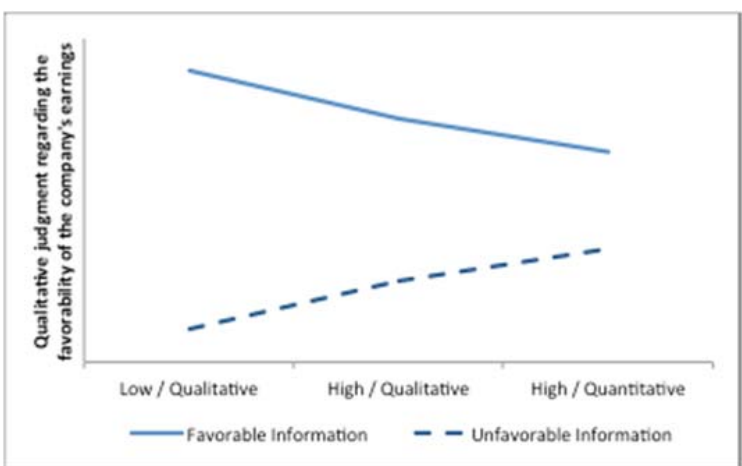

\section{Quantitative Earnings Judgments}

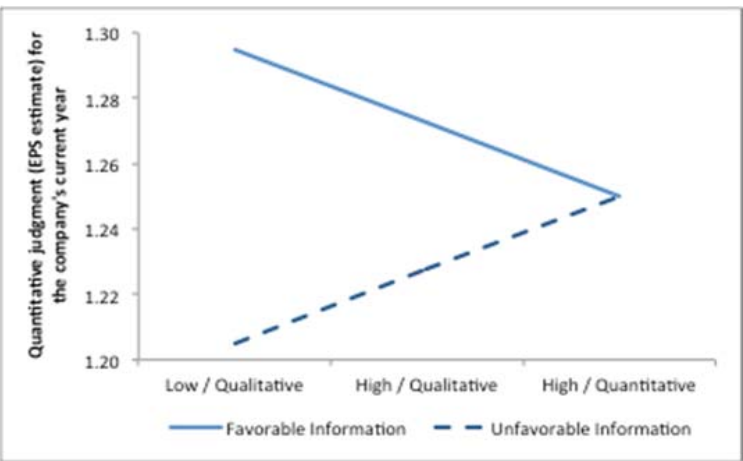

This figure pictorially represents my experimental predictions for the two earnings judgments participants are asked to make. The first (second) diagram shows the expected results for the qualitative (quantitative) earnings measure. These diagrams are used to test my hypothesis as described below.

Hypothesis 1a suggests that when the managerial bias is unknown (i.e. in the low bias conditions for both diagrams above) investor judgments are influenced by the type of information communicated, either favorable or unfavorable information.

Hypothesis $1 \mathrm{~b}$ details how investors will be unable to adjust for the known bias in managerial communications, except in one specific instance. Investors may fully unravel the bias when they know the precise magnitude of the bias and then make compatible quantitative judgments regarding the company's earnings per share (i.e. in diagram II above for the high bias / quantitative information conditions). 
Figure 3: Actual results - investors' qualitative earnings judgments (favorability of earnings), quantitative earnings judgments (EPS estimates), and investment decisions (likelihood of investment) by experimental condition

I. Qualitative Earnings Judgments

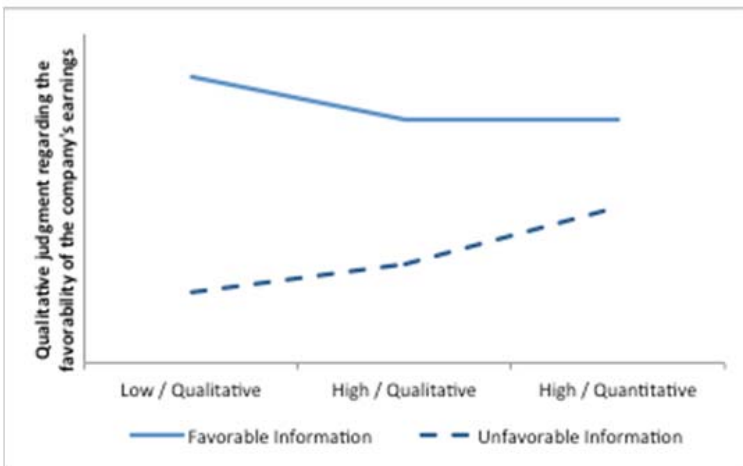

\section{Quantitative Earnings Judgments}

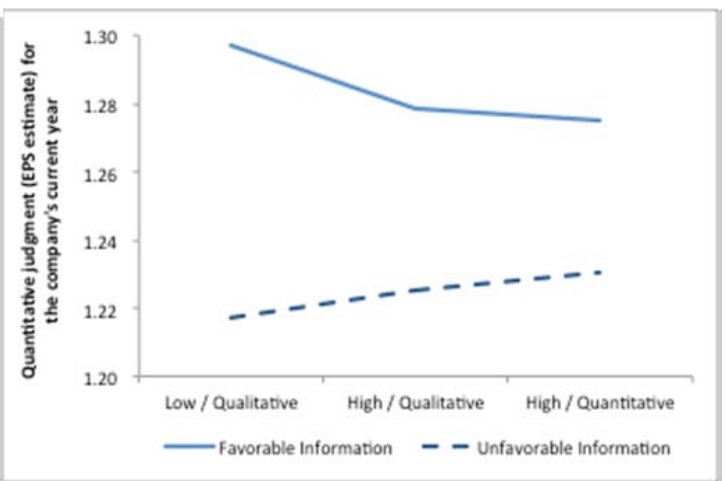

\section{Investment Decision}

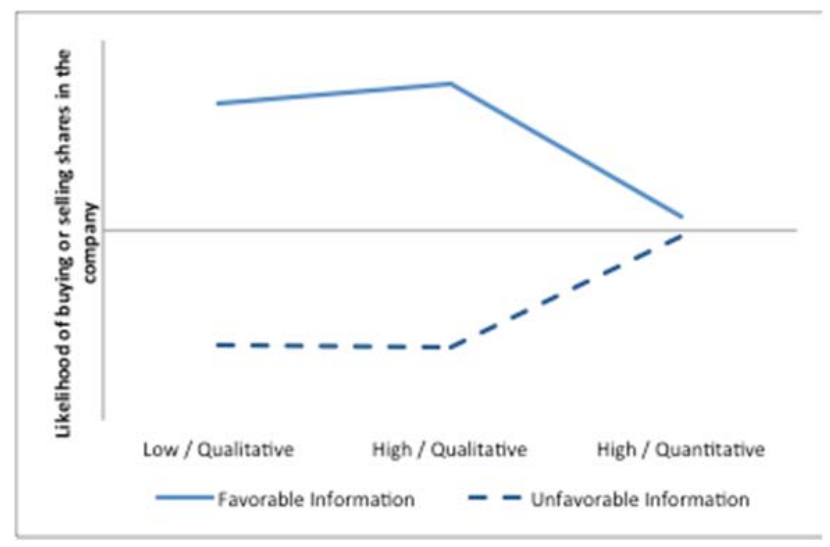

These diagrams display the actual results from my experiment and indicate that investors are unable to fully adjust for known bias in manager communications for any earnings-related judgment. See table 2 for descriptions of the variables and statistical tests corresponding to each of these measures. 
Figure 4: Structural Equation Model as Predicted by the Belief Bias

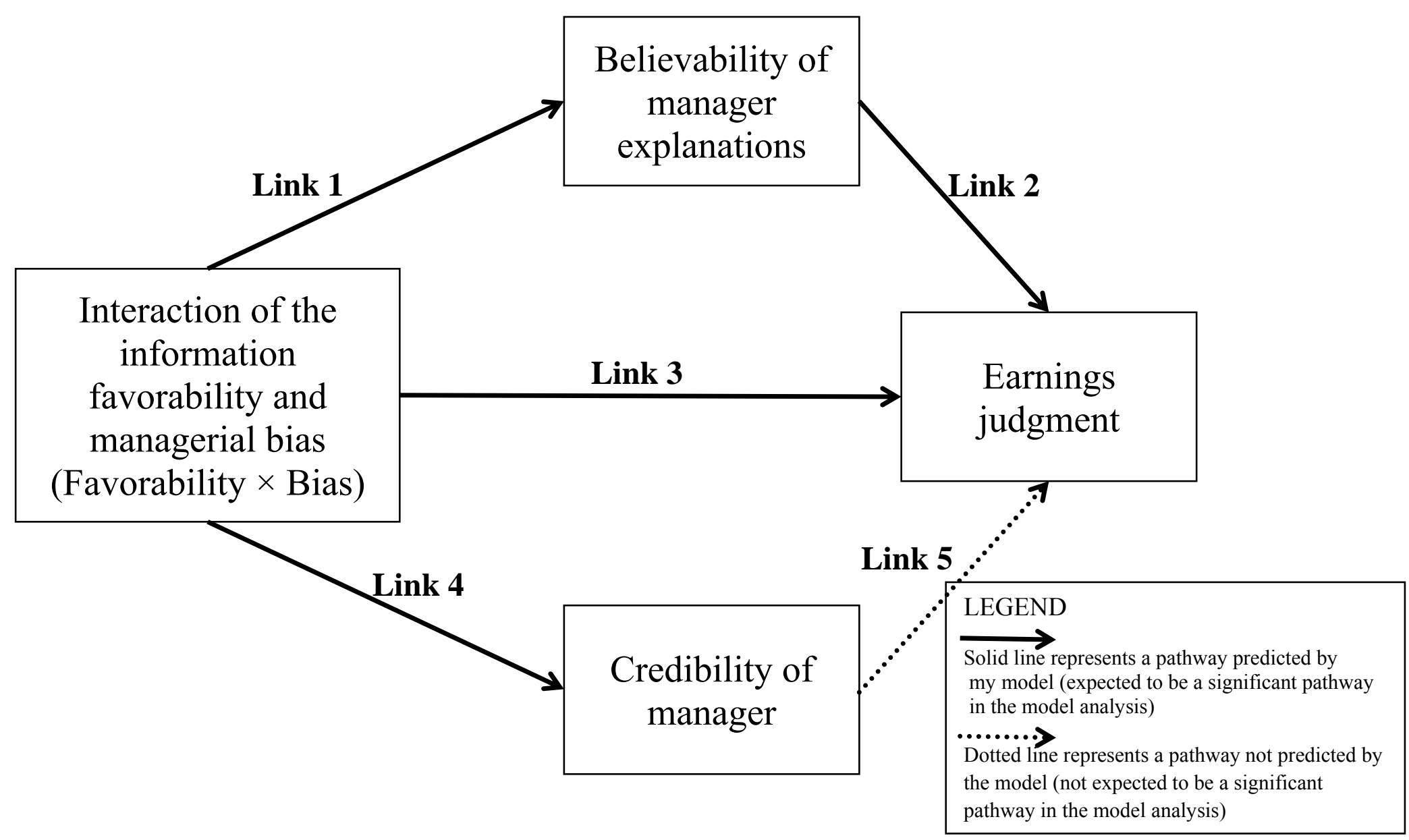


Figure 4 depicts the causal model as predicted by the belief bias. The belief bias suggests that investors focus on the believability of managerial explanations and pay insufficient attention to the reliability of those explanations. Thus, the model predicts that the believability judgments will significantly impact earnings judgments while judgments concerning the credibility of management will not significantly impact earnings judgments. 
Figure 5: Structural Equation Model Results

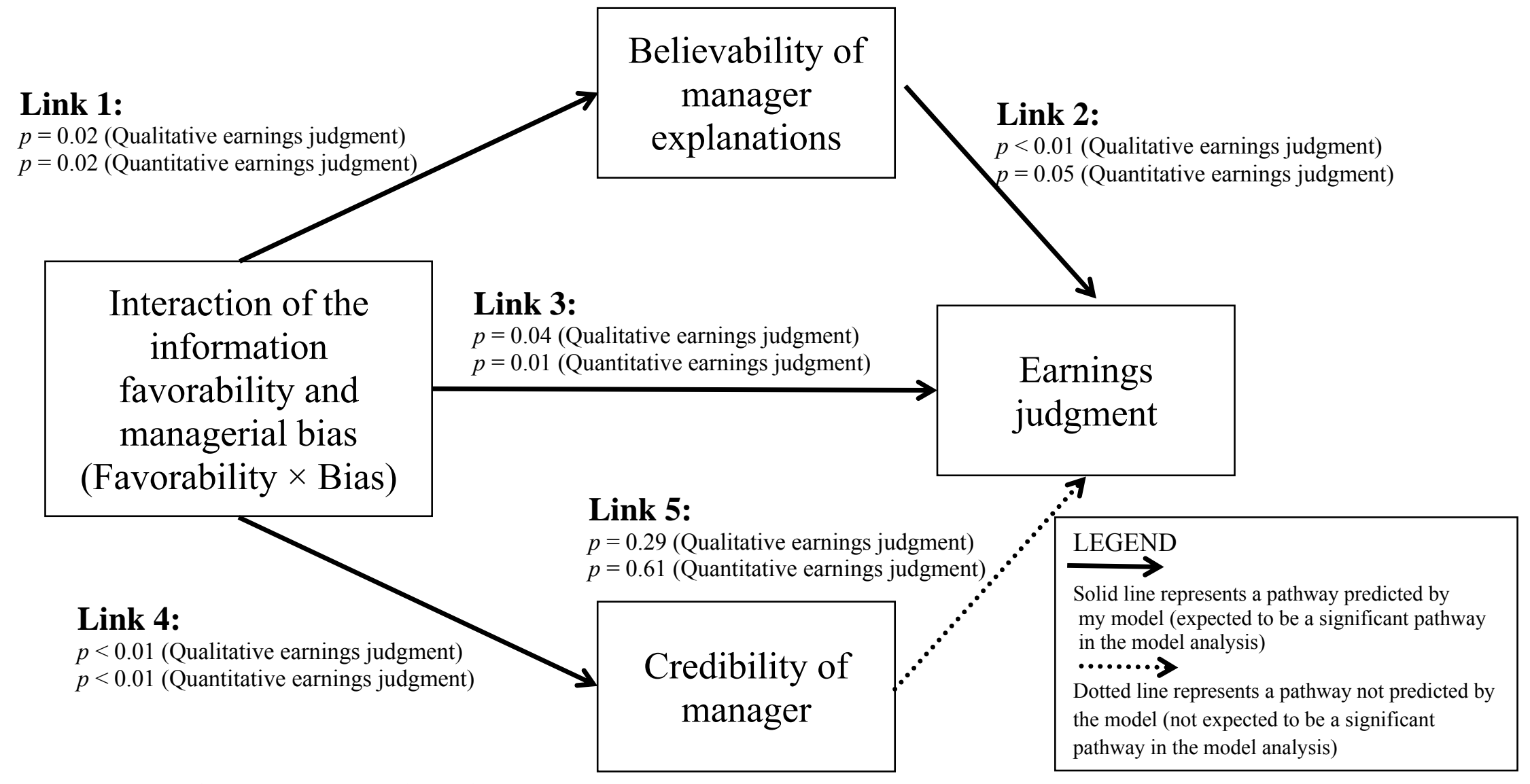

Indirect Paths (including path significance):

1) Favorability $\times$ bias $\rightarrow$ Believability $\rightarrow$ Qualitative earning judgment (links $1 \& 2) \quad(p=0.06)$

2) Favorability $\times$ bias $\rightarrow$ Believability $\rightarrow$ Quantitative earning judgment (links $1 \& 2) \quad(p=0.14)$

3) Favorability $\times$ bias $\rightarrow$ Credibility $\rightarrow$ Qualitative earning judgment (links 4 \& 5) $\quad(p=0.31)$

4) Favorability $\times$ bias $\rightarrow$ Credibility $\rightarrow$ Quantitative earning judgment (links $4 \& 5) \quad(p=0.62)$ 
Figure 5 provides a graphical representation of the relevant results of the path analysis employed in this study. Two independent models were analyzed. The first includes the qualitative earnings measure as the earnings judgement variable and the second includes the quantitative earnings measure as the earnings judgment variable. Structural equation analysis was performed using mPlus software. The findings support my predictions and provide evidence that investors' judgments are influenced by the belief bias. Direct effects from the independent variables (level of bias and information favorability) to all dependent measures are included in the analysis of the model. To reduce the clutter in the diagram these variables are not included above. 


\section{APPENDICES}


APPENDIX A: EXPERIMENTAL MATERIALS 


\section{GENERAL INSTRUCTIONS}

Thank you for participating. Your total participation time should be approximately 15-20 minutes.

Keep in mind that the case information you will receive is not intended to include all the information that would potentially be available if you were in a real-world situation. However, for purposes of this study, base your judgments on the information provided. Further, there are not right or wrong answers; I am only interested in your judgments.

Should you have any questions during this study, please do not hesitate to ask those questions. However, please do not discuss this study with others until the study is over.

Thank you again for your participation.

\section{James Smith}

James Smith

PhD Candidate in Accounting

McCombs School of Business 
Assume that it is now May 1, 2011. Further, assume that you are a manager for an investment management firm. You obtained the following information about Omega Company.

\section{OMEGA COMPANY}

\section{Company Background}

Omega Company is a Florida-based company that manufacturers water filtration systems. The Company's filtration systems utilize sand and diatomaceous earth as the main types of filter mediums. Omega sells these filtration systems, both domestically and worldwide, to residential and industrial customers. The Company's fiscal year end is December 31.

The Company is one of the largest manufacturers in their industry. While Omega is based in the United States, a significant portion of their sales comes from international customers. Omega's customer base is very diverse. For instance, Omega's various products are used by individual households in rural areas who only have access to untreated well water. Also, large industrial customers use Omega's products to filter and recycle water in their manufacturing processes.

\section{Additional Information}

Residential filtration systems typically utilize sand as the primary filter medium. Sand filters are easier to maintain and provide an acceptable level of filtration for most residential needs.

Industrial filtration systems often utilize diatomaceous earth as a filter medium. These filters are able to remove particles in water that would otherwise pass through sand filters. However, diatomaceous earth filters require significantly more care and maintenance than sand filters.

\section{Analyst Forecast Information}

In April of this year, the consensus analyst forecast for Omega's 2011 earnings was $\$ 1.26$ per share. This consensus analyst forecast represents the average of the earnings forecasts provided by the Wall Street analysts that follow Omega. 


\section{APPENDIX B: EXPERIMENTAL MANIPULATIONS}




\title{
Favorable Disclosure, Low Bias / Qualitative Description
}

\author{
NEWS RELEASE
}

You now read the following from the Business Wire.

Omega CEO Provides a Positive (Negative) Outlook on the Company's 2011 Earnings Forecast

May 1, 2011. JACKSONVILLE, FL.--(BUSINESS

WIRE)--Today Tom Miller, Omega Company's CEO, released a statement to the media.

"Omega competes around the world in various geographic regions. Diverse economic factors and changing consumer preferences are likely to favorably (unfavorably) impact Omega's earnings in the current year. In particular, we believe that Omega's profit margins will improve (weaken). We expect declining (increasing) material costs following our upcoming annual negotiations with suppliers. The demand for Omega's products is likely to increase (decrease) in the coming months. We anticipate an influx of (a reduction in) international customers in the near term. We also believe that operational efficiencies could lower costs in the coming year. (We also believe that administrative complexities could increase costs in the coming year.)

Based on these factors, our 2011 earnings forecast is \$1.31 (\$1.21) per share. This forecast is higher (lower) than the consensus analyst forecast from April of $\$ 1.26$ per share."

You know that a forecast issued by a company could be fairly accurate where it provides a good estimate of the actual earnings that are later reported. You also know that a company-provided forecast could be inaccurate in one of two ways. Specifically, it could be inaccurate in an optimistic direction where the company-provided forecast is higher than the actual earnings that are later reported. Alternatively, it could be inaccurate in a pessimistic direction where the company-provided forecast is lower than the actual earnings that are later reported.

Historically, Tom Miller (CEO of Omega) has issued forecasts that have been fairly accurate. 


\title{
Unfavorable Disclosure, Low Bias / Qualitative Descriptions
}

\author{
NEWS RELEASE
}

You now read the following from the Business Wire.

Omega CEO Provides a Positive (Negative) Outlook on the Company's 2011 Earnings Forecast

May 1, 2011. JACKSONVILLE, FL.--(BUSINESS

WIRE)--Today Tom Miller, Omega Company's CEO, released a statement to the media.

"Omega competes around the world in various geographic regions. Diverse economic factors and changing consumer preferences are likely to favorably (unfavorably) impact Omega's earnings in the current year. In particular, we believe that Omega's profit margins will improve (weaken). We expect declining (increasing) material costs following our upcoming annual negotiations with suppliers. The demand for Omega's products is likely to increase (decrease) in the coming months. We anticipate an influx of (a reduction in) international customers in the near term. We also believe that operational efficiencies could lower costs in the coming year. (We also believe that administrative complexities could increase costs in the coming year.)

Based on these factors, our 2011 earnings forecast is \$1.31 (\$1.21) per share. This forecast is higher (lower) than the consensus analyst forecast from April of $\$ 1.26$ per share."

You know that a forecast issued by a company could be fairly accurate where it provides a good estimate of the actual earnings that are later reported. You also know that a company-provided forecast could be inaccurate in one of two ways. Specifically, it could be inaccurate in an optimistic direction where the company-provided forecast is higher than the actual earnings that are later reported. Alternatively, it could be inaccurate in a pessimistic direction where the company-provided forecast is lower than the actual earnings that are later reported.

Historically, Tom Miller (CEO of Omega) has issued forecasts that have been fairly accurate. 


\title{
Favorable Disclosure, High Bias / Qualitative Descriptions
}

\author{
NEWS RELEASE
}

You now read the following from the Business Wire.

Omega CEO Provides a Positive (Negative) Outlook
on the Company’s 2011 Earnings Forecast

May 1, 2011. JACKSONVILLE, FL.--(BUSINESS

WIRE)--Today Tom Miller, Omega Company's CEO, released a statement to the media.

"Omega competes around the world in various geographic regions. Diverse economic factors and changing consumer preferences are likely to favorably (unfavorably) impact Omega's earnings in the current year. In particular, we believe that Omega's profit margins will improve (weaken). We expect declining (increasing) material costs following our upcoming annual negotiations with suppliers. The demand for Omega's products is likely to increase (decrease) in the coming months. We anticipate an influx of (a reduction in) international customers in the near term. We also believe that operational efficiencies could lower costs in the coming year. (We also believe that administrative complexities could increase costs in the coming year.)

Based on these factors, our 2011 earnings forecast is $\$ 1.31$ (\$1.21) per share. This forecast is higher (lower) than the consensus analyst forecast from April of $\$ 1.26$ per share."

You know that a forecast issued by a company could be fairly accurate where it provides a good estimate of the actual earnings that are later reported. You also know that a company-provided forecast could be inaccurate in one of two ways. Specifically, it could be inaccurate in an optimistic direction where the company-provided forecast is higher than the actual earnings that are later reported. Alternatively, it could be inaccurate in a pessimistic direction where the company-provided forecast is lower than the actual earnings that are later reported.

Historically, Tom Miller (CEO of Omega) has issued forecasts that have been fairly inaccurate. In particular, his forecasts have always differed from actual earnings in the same direction that his current forecast differs from the April consensus analyst forecast noted above. 


\title{
Unfavorable Disclosure, High Bias / Qualitative Descriptions
}

\author{
NEWS RELEASE
}

You now read the following from the Business Wire.

Omega CEO Provides a Positive (Negative) Outlook
on the Company's 2011 Earnings Forecast

May 1, 2011. JACKSONVILLE, FL.--(BUSINESS

WIRE)--Today Tom Miller, Omega Company's CEO, released a statement to the media.

"Omega competes around the world in various geographic regions. Diverse economic factors and changing consumer preferences are likely to favorably (unfavorably) impact Omega's earnings in the current year. In particular, we believe that Omega's profit margins will improve (weaken). We expect declining (increasing) material costs following our upcoming annual negotiations with suppliers. The demand for Omega's products is likely to increase (decrease) in the coming months. We anticipate an influx of (a reduction in) international customers in the near term. We also believe that operational efficiencies could lower costs in the coming year. (We also believe that administrative complexities could increase costs in the coming year.)

Based on these factors, our 2011 earnings forecast is $\$ 1.31$ (\$1.21) per share. This forecast is higher (lower) than the consensus analyst forecast from April of $\$ 1.26$ per share."

You know that a forecast issued by a company could be fairly accurate where it provides a good estimate of the actual earnings that are later reported. You also know that a company-provided forecast could be inaccurate in one of two ways. Specifically, it could be inaccurate in an optimistic direction where the company-provided forecast is higher than the actual earnings that are later reported. Alternatively, it could be inaccurate in a pessimistic direction where the company-provided forecast is lower than the actual earnings that are later reported.

Historically, Tom Miller (CEO of Omega) has issued forecasts that have been fairly inaccurate. In particular, his forecasts have always differed from actual earnings in the same direction that his current forecast differs from the April consensus analyst forecast noted above. 


\section{Favorable Disclosure, High Bias / Quantitative Descriptions}

NEWS RELEASE

You now read the following from the Business Wire.

Omega CEO Provides a Positive (Negative) Outlook

on the Company's 2011 Earnings Forecast

May 1, 2011. JACKSONVILLE, FL.--(BUSINESS

WIRE)--Today Tom Miller, Omega Company's CEO, released a statement to the media.

"Omega competes around the world in various geographic regions. Diverse economic factors and changing consumer preferences are likely to favorably (unfavorably) impact Omega's earnings in the current year. In particular, we believe that Omega's profit margins will improve (weaken). We expect declining (increasing) material costs following our upcoming annual negotiations with suppliers. The demand for Omega's products is likely to increase (decrease) in the coming months. We anticipate an influx of (a reduction in) international customers in the near term. We also believe that operational efficiencies could lower costs in the coming year. (We also believe that administrative complexities could increase costs in the coming year.)

Based on these factors, our 2011 earnings forecast is $\$ 1.31$ (\$1.21) per share. This forecast is higher (lower) than the consensus analyst forecast from April of $\$ 1.26$ per share."

You know that a forecast issued by a company could be fairly accurate where it provides a good estimate of the actual earnings that are later reported. You also know that a company-provided forecast could be inaccurate in one of two ways. Specifically, it could be inaccurate in an optimistic direction where the company-provided forecast is higher than the actual earnings that are later reported. Alternatively, it could be inaccurate in a pessimistic direction where the company-provided forecast is lower than the actual earnings that are later reported.

Historically, Tom Miller (CEO of Omega) has issued forecasts that have been fairly inaccurate. In particular, his forecasts have always differed from actual earnings in the same direction that his current forecast differs from the April consensus analyst forecast noted above.

Further, the dollar magnitude of the difference between Tom Miller's (CEO of Omega) forecasts and actual earnings that are later reported has always been five cents per share. 


\section{Unfavorable Disclosure, High Bias / Quantitative Descriptions}

NEWS RELEASE

You now read the following from the Business Wire.

Omega CEO Provides a Positive (Negative) Outlook

on the Company's 2011 Earnings Forecast

May 1, 2011. JACKSONVILLE, FL.--(BUSINESS

WIRE)--Today Tom Miller, Omega Company's CEO,

released a statement to the media.

"Omega competes around the world in various

geographic regions. Diverse economic factors and changing consumer preferences are likely to favorably

(unfavorably) impact Omega's earnings in the current year. In particular, we believe that Omega's profit margins will improve (weaken). We expect declining (increasing) material costs following our upcoming annual negotiations with suppliers. The demand for Omega's products is likely to increase (decrease) in the coming months. We anticipate an influx of (a reduction in) international customers in the near term. We also believe that operational efficiencies could lower costs in the coming year. (We also believe that administrative complexities could increase costs in the coming year.)

Based on these factors, our 2011 earnings forecast is $\$ 1.31$ (\$1.21) per share. This forecast is higher (lower) than the consensus analyst forecast from April of $\$ 1.26$ per share."

You know that a forecast issued by a company could be fairly accurate where it provides a good estimate of the actual earnings that are later reported. You also know that a company-provided forecast could be inaccurate in one of two ways. Specifically, it could be inaccurate in an optimistic direction where the company-provided forecast is higher than the actual earnings that are later reported. Alternatively, it could be inaccurate in a pessimistic direction where the company-provided forecast is lower than the actual earnings that are later reported.

Historically, Tom Miller (CEO of Omega) has issued forecasts that have been fairly inaccurate. In particular, his forecasts have always differed from actual earnings in the same direction that his current forecast differs from the April consensus analyst forecast noted above.

Further, the dollar magnitude of the difference between Tom Miller's (CEO of Omega) forecasts and actual earnings that are later reported has always been five cents per share. 
APPENDIX C: EXPERIMENTAL QUESTIONS 


\section{QUESTIONS}

Unless otherwise noted, you are free to look back at the case materials when answering the following questions.

Answer the questions in the order they appear. After you have answered a question, please do not go back and change your response.

When a scale is provided, please place a slash mark ( / ) on the point of the scale that corresponds to your judgment.

1. Based on the available information, I believe that Omega's actual earnings for 2011 will be . (Answer using the scale below)

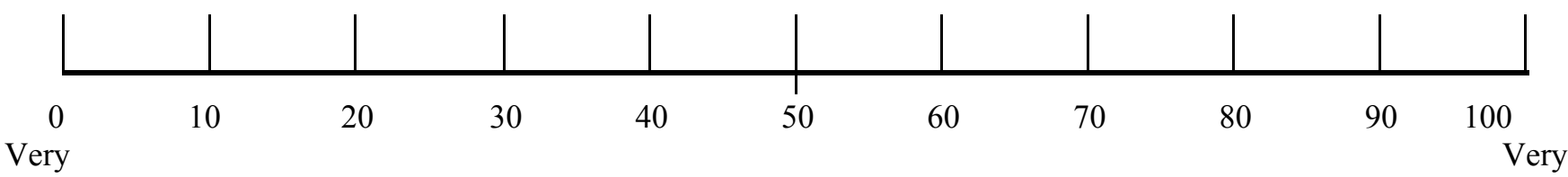

Unfavorable

Favorable

2. I am about my judgment above in question 1.

\begin{tabular}{|c|c|c|c|c|c|c|c|c|c|c|}
\hline $\begin{array}{l}0 \\
\text { ry } \\
\text { isure }\end{array}$ & 10 & 20 & 30 & 40 & 50 & 60 & 70 & 80 & 90 & $\begin{array}{l}100 \\
\text { Very } \\
\text { Sure }\end{array}$ \\
\hline
\end{tabular}

3. Based on the available information, I believe that Omega's actual earnings for 2011 will be:

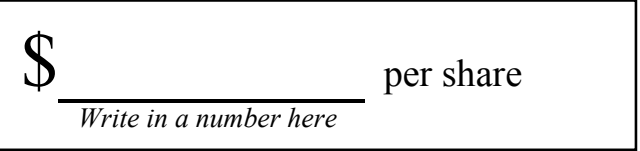

4. I am about my judgment above in question 3 .

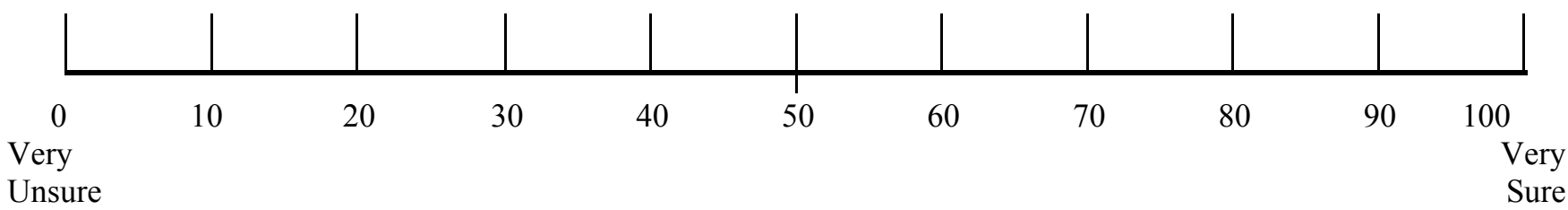




\section{QUESTIONS CONTINUED}

5. You decide to determine a fair price for Omega's shares. To do this, assume that you think about the price-earnings $(\mathrm{P} / \mathrm{E})$ multiple that should be applied to your belief about Omega's actual earnings for 2011 (i.e., the earnings per share number you provided in question 3 on the prior page). What would that multiple be?

Assume that other firms in the industry trade at multiples of earnings of between 10 and 20 times forecasted earnings.
Your estimate of 2011 actual earnings
(the number you provided in question 3
$\mathrm{X}$

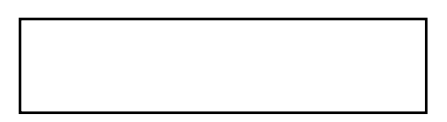
$=$ Reasonable stock price
Write in a P/E multiple (number) here

NOTE: A low multiple means you wouldn't be willing to pay much for the company, while a higher multiple means you would be willing to pay more for the company. 


\section{QUESTIONS CONTINUED}

6. For this question, assume that you currently manage a diversified stock portfolio. Included in your portfolio are 10,000 shares of Omega stock. Based on the information provided in this case, how likely is it that you buy additional stock in Omega Company or sell stock in Omega Company? (Assume that you currently have some uninvested funds available to purchase additional common stock, if you wish to do so.)

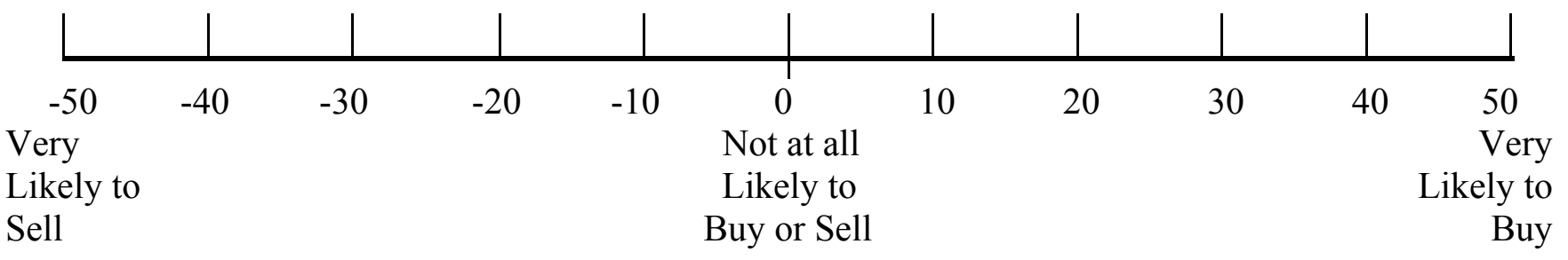

7. Ignoring commissions, how many shares of Omega would you buy or sell? (Assume that you have enough funds to buy 10,000 additional shares of Omega stock.)

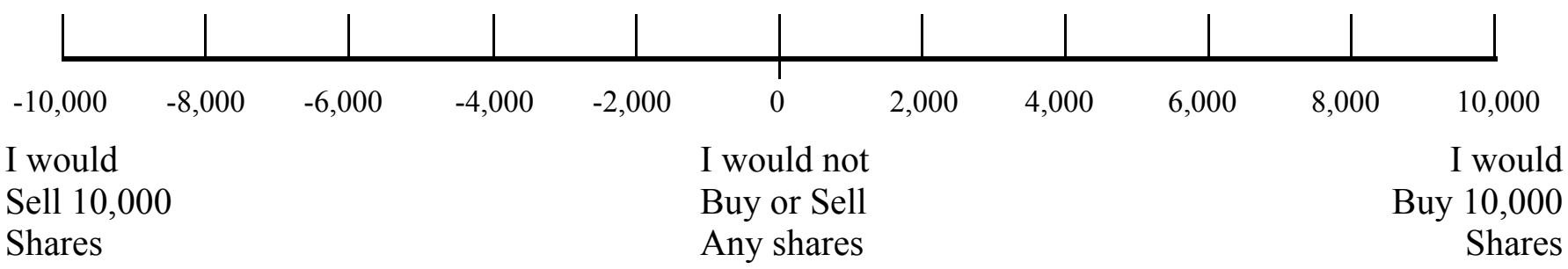




\section{QUESTIONS CONTINUED}

8. I believe that an investment in Omega's stock is

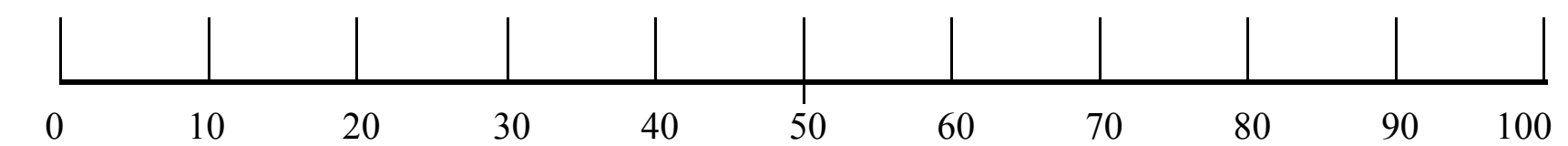

Not at all

Risky

Very

Risky 
APPENDIX D: QUESTIONS ABOUT THE PRESS RELEASE 


\section{QUESTIONS ABOUT OMEGA'S NEWS RELEASE}

Please do not refer back to the previous pages when answering the following questions.

The next two questions relate to the believability of two components of Omega's news release - the believability of the earnings forecast and the believability of the reasons provided by Tom Miller, CEO of Omega.

Try to think about each component separately and then rate them.

1. I believe that Omega's earnings forecast, as contained in Omega's news release, was

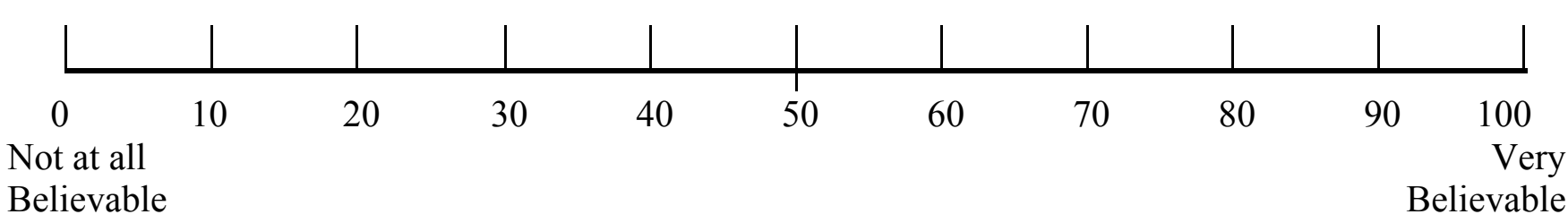

2. I believe that the CEO's reasons provided in the news release were

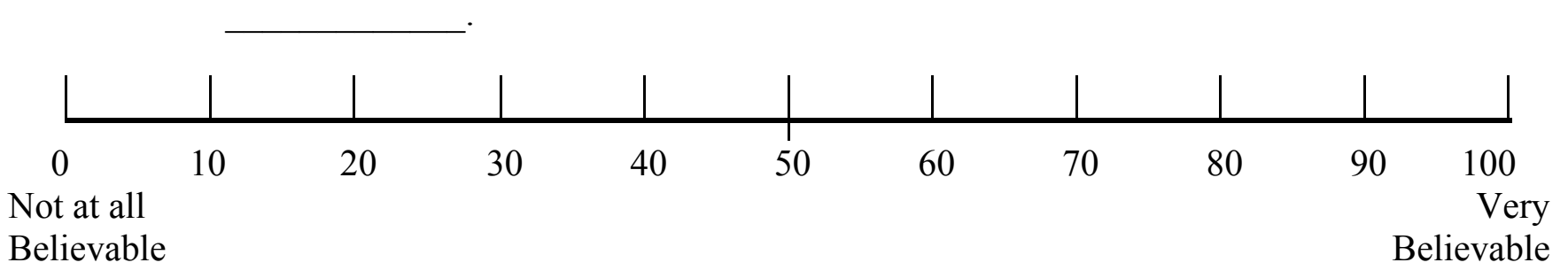


APPENDIX E: ADDITIONAL PROCESS-RELATED QUESTIONS 


\section{OTHER QUESTIONS}

Please do not refer back to the previous pages when answering the following questions.

1. Based on the information provided to me in the case, I thought it was for me to predict Omega's actual earnings for 2011.

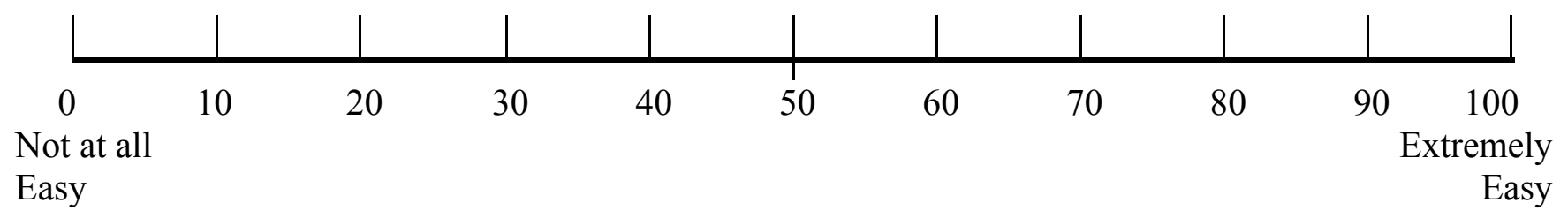

2. I believe that Omega's CEO, Tom Miller, was

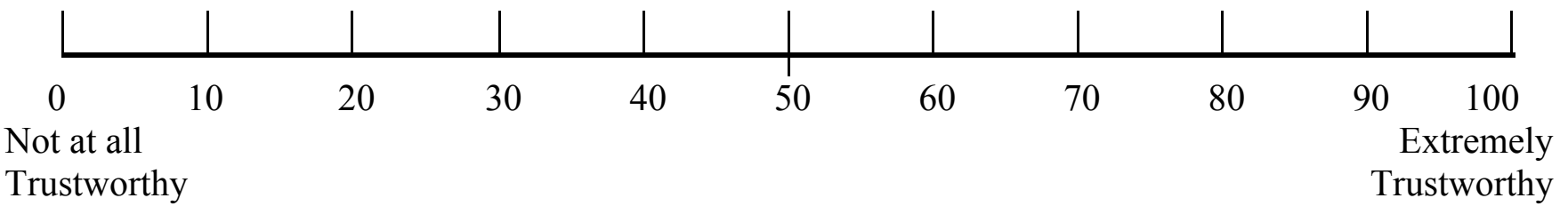

3. I believe that Omega's CEO, Tom Miller, was

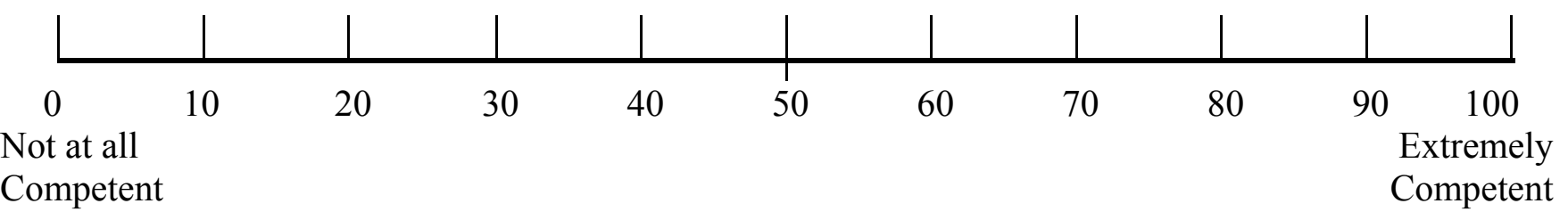

4. I believe that the CEO's earnings forecast for 2011 was as compared to what the Company's actual earnings will be in 2011.

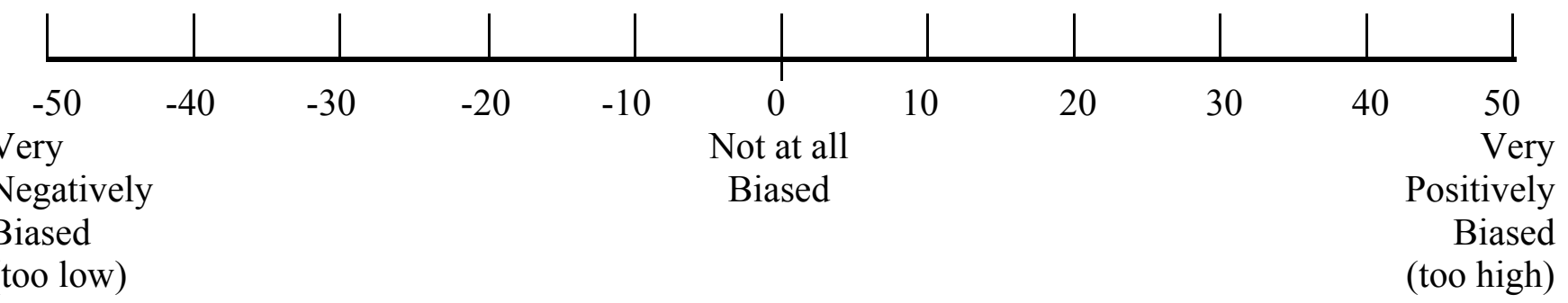




\section{OTHER QUESTIONS CONTINUED}

5. Based on the information provided to me, I believe that it was that Tom Miller (Omega's CEO) strategically provided a forecast so that Omega Company's actual earnings would meet or beat that forecast.

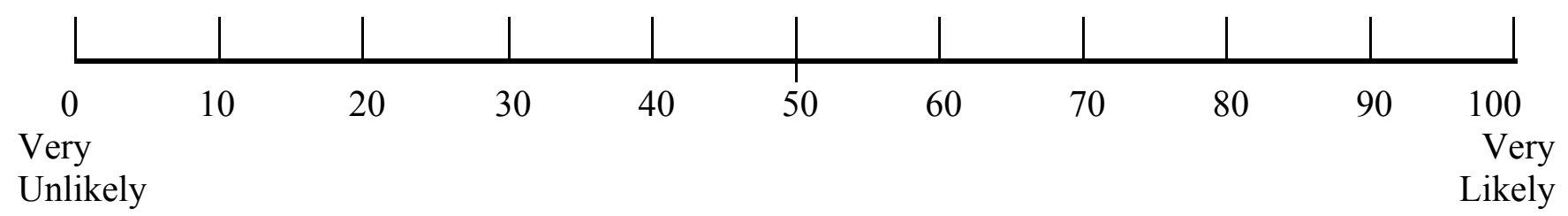

6. Based on the information provided, it is that the consensus analyst forecast from April was biased.

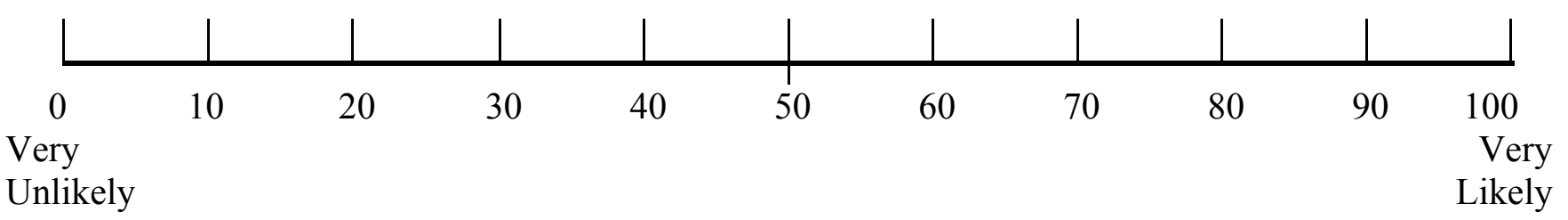


APPENDIX F: MANIPULATION CHECK AND DEMOGRAPHIC DETAIL QUESTIONS 


\section{GENERAL QUESTIONS}

Again, please do not refer back to the previous pages when answering the following questions.

1. Recall that the consensus analyst forecast for Omega Company was $\$ 1.26$ per share. In the news release, Tom Miller (Omega's CEO) provided a forecast for 2011 earnings of

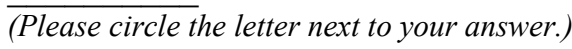
a. \$1.21 per share.
b. \$1.31 per share.
c. I don't recall.

2. In the news release, the reasons provided for Omega's 2011 earnings forecast suggest a outlook for Omega.
a. Positive.
b. Negative.
c. I don't recall.

3. Historically, Tom Miller (Omega's CEO) has issued forecasts that have been fairly

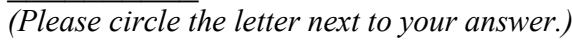
a. Accurate.
b. Inaccurate.
c. I don't recall.

4. Think back to the information you were provided regarding Omega Company. Indicate whether the following fact was presented in that information.

FACT: The dollar magnitude of the difference between Tom Miller's (CEO of Omega) forecasts and actual earnings that are later reported has always been five cents per share.

Yes, this fact was included in the information provided.

No, this fact was not included in the information provided. 


\section{ADDITIONAL QUESTIONS}

To help me better understand why your responses might differ from those of your colleagues, please answer the following questions. There are no wrong or right answers.

1. Have you ever made investments in the common stock of a company? YES NO

If yes, approximately how many times? ___ times

2. Do you plan to invest in the common stock of a company at some time in the future?

YES NO

3. Have you ever made investments in a common stock mutual fund?

YES NO

4. How many undergraduate and graduate finance and accounting courses have you taken, including those you are taking this semester?

Finance

Accounting

5. How many years of previous work experience do you have? years

6. Have you ever worked in the following capacities?

If yes, fill in the number of years. If no, leave blank.

Corporate finance

years

Corporate accounting

years

Engineering, operations, or other technical position

years

Public accounting

years

Management

years

Other

years

THANK YOU FOR PARTICIPATING IN THIS STUDY.

PLEASE RETURN ALL MATERIALS. 


\section{Works Cited}

Abarbanell, Jeffery and Reuven Lehavy. 2003. Biased forecasts or biased earnings? The role of reported earnings in explaining apparent bias and over/underreaction in analysts' earnings forecasts. Journal of Accounting and Economics 36 (1-3): 105-146.

Aboody, David, Mary E. Barth, and Ron Kasznik. 2004. Firms' voluntary recognition of stock- based compensation expense. Journal of Accounting Research 42 (2): 123-150.

Arkes, Hal R. 1991. Costs and benefits of judgment errors: implications for debiasing. Psychological Bulletin 110 (3): 486-498.

Baginski, Stephen P., John M. Hassell, and Michael D. Kimbrough. 2004. Why Do Managers Explain their Earnings Forecasts? Journal of Accounting Research 42 (1): $1-29$.

Bamber, Linda, Kai Hui, and P. Eric Yeung. 2010. Managers' EPS forecasts: nickeling and diming the market? The Accounting Review 85 (1): 63-95.

Barth, Mary E., Ian D. Gow, and Daniel J. Taylor. 2010. Non-GAAP and street earnings: evidence from SFAS 123R (September 1, 2010). Rock Center for Corporate Governance at Stanford University Working Paper No. 88. Available at SSRN: http://ssrn.com/abstract=1681144

Bartov, Eli, Dan Givoly and Carla Hayn. 2002. The rewards to meeting or beating earnings expectations. Journal of Accounting and Economics 33 (2): 173-204.

Bernard, Victor and Douglas Skinner. 1996. What motivates managers' choice of discretionary accruals? Journal of Accounting and Economics 22 (1-3): 313-325.

Beyer, Anne, Daniel A. Cohen, Thomas Z. Lys, and Beverly R. Walther. 2010. The 86 
financial reporting environment: Review of the recent literature. Journal of Accounting and Economics 50 (2-3): 296-343.

Beyth-Marom, Ruth and Baruch Fischhoff. 1983. Diagnosticity and pseudodiagnosticity. Journal of Personality and Social Psychology 45 (6): 1185-1195.

Birnbaum, Michael H. and Steven E. Stegner. 1979. Source credibility in social judgment: Bias, expertise, and the judge's point of view. Journal of Personality and Social Psychology 37 (1): 48-74.

Bolton, Patrick, Jose Scheinkman, and Wei Xiong. 2006. Executive compensation and short- termist behavior in speculative markets. Review of Economic Studies 73 (3): 577- 610 .

Bryan Stephen, LeeSeok Hwang and Steven Lilien. 2000. CEO stock based compensation: An empirical analysis of incentive intensity, relative mix, and economic determinants. The Journal of Business 73 (4): 661-693.

Burgoon, Judee K., J. Pete Blair, and Renee E. Strom. 2008. Cognitive biases and nonverbal cue availability in detecting deception. Human Communication Research 34 (4): 572-599.

Burgstahler, David and Ilia Dichev. 1997. Earnings management to avoid earnings decreases and losses. Journal of Accounting and Economics 24 (1): 99-126.

Bushman, Robert M., and Raffi J. Indjejikian. 1993. Accounting income, stock price and managerial compensation. Journal of Accounting and Economics 16 (1-3): 3-23

Camerer, Colin F. and Robin M. Hogarth. 1999. The effects of financial incentives in experiments: A review of capital-labor-production framework. Journal of Risk and Uncertainty 19 (1-3): 7-42.

Chan, Elaine and Jaideep Sengupta. 2010. Insincere flattery actually works: A dual 
attitudes perspective. Journal of Marketing Research 47 (1): 122-133.

Chen, Qi, Thomas Hemmer, and Yun Zhang. 2007. On the relation between conservatism in accounting standards and incentives for earnings management. Journal of Accounting Research 45 (3): 541-565.

Connolly, Terry and Marcel Zeelenberg. 2002. Regret in decision making. Current Directions in Psychological Science 11 (): 212-220

Daniel, Kent, David Hirshleifer and Siew Hong Teoh. 2002. Investor psychology in capital markets: evidence and policy implications. Journal of Monetary Economics 49 (1): 139-209.

Dechow, Patricia and Douglas Skinner. 2000. Earnings management: Reconciling the views of accounting academics, practitioners, and regulators. Accounting Horizons 14 (2): $235-250$.

Dye, Ronald. 1988. Earnings Management in an Overlapping Generations Model. Journal of Accounting Research 26 (2): 195-235.

Elliott, W. Brooke, Frank D. Hodge, S. Jane Kennedy, and Maarten Pronk. 2007. Are M.B.A. students a good proxy for non-professional investors? The Accounting Review 81 (1): $139-168$.

Evans, J. St. B. T., Julie L. Barston, and Paul Pollard. 1983. On the conflict between logic and belief in syllogistic reasoning. Memory and Cognition, 11, 295-306.

Financial Accounting Standards Board. 1980. Statement of Financial Accounting Concepts No. 2: Qualitative characteristics of accounting information. Norwalk, CT.

Fama, Eugene. 1970. Efficient Capital markets: A review of theory and empirical work. The Journal of Finance 25 (2): 383-417. 
Fama, Eugene. 1998. Market efficiency, long-term returns, and behavioral finance. Journal of Financial Economics 49 (3): 283-306.

Fischer, Gregory W. and Scott A. Hawkins. 1993. Strategy compatibility, scale compatibility, and the prominence effect. Journal of Experimental Psychology: Human Perception and Performance 19 (3): 580-597.

Fischhoff, Baruch, and Ruth Beyth-Marom. 1983. Hypothesis evaluation from a Bayesian perspective. Psychological Review 90 (3): 239-260.

Ganguly, Ananda R., John H. Kagel, and Donald V. Moser. 1994. The effects of biases in probability judgments on market prices. Accounting, Organizations and Society 19 (8): $675-700$.

Gilbert, Daniel. 1991. How mental systems believe. American Psychologist 46 (2): 107119.

Gilbert, Daniel T., Romin W. Tafarodi, and Patrick S. Malone. 1993. You can't not believe everything you read. Journal of Personality and Social Psychology 65 (2): 221-233.

Gilinsky, Alberta S. and Ben B. Judd. 1994. Working memory and bias in reasoning across the life span. Psychology and Aging 9 (3): 356-371.

Herrmann, Don and Wayne B. Thomas. 2005. Rounding of analyst forecasts. The Accounting Review 80 (3): 805-823.

$\mathrm{Hu}, \mathrm{Li}$-tze and Peter M. Bentler. 1999. Cutoff criteria for fit indexes in covariance structure analysis: conventional criteria versus new alternatives. Structural Equation Modeling, 6 (1): 1-55

Hugon, Artur and K. C. Lin. 2010. Misleading earnings guidance. Working paper (December 2010). 
Hutton, Amy P., Gregory S. Miller, and Douglas J. Skinner. 2003. The role of supplementary statements with management earnings forecasts. Journal of Accounting Research 41 (5): 867-890.

Jacob, John, Thomas Lys, and Jowell Sabino. 1999. Autocorrelation structure of forecast errors from time-series models: Alternative assessments of the causes of postearnings announcement drift. Journal of Accounting and Econnomics 28 (3): 329358.

Jensen, Michael C. 1986. Agency costs of free cash flow, corporate finance, and takeovers. American Economic Review 76 (2): 323-329.

Jones, Martin and Robert Sudgen. 2001. Positive confirmation bias in the acquisition of information. Theory and Decision 50 (1): 59-99.

Kanodia, Chandra, Rajdeep Singh, and Andrew E. Spero. 2005. Imprecision in accounting measurement: Can it be value enhancing? Journal of Accounting Research 43 (3): 487-519.

Kothari, S. P., Xu Li, and James E. Short. 2009. The effect of disclosures by management, analysts, and business press on cost of capital, return volatility, and analyst forecasts: A study using content analysis. The Accounting Review 84 (5): 1639-1670.

Koonce, Lisa, Mary L. McAnally, and Molly Mercer. 2005. How do investors judge the risk of financial items? The Accounting Review 80 (1): 221-241.

Kunda, Ziva. 1990. “The case for motivated political reasoning. Psychological Bulletin 108 (3): 480-98.

Larrick, Richard P. and Terry L. Boles. 1995. Avoiding regret in decision with feedback: A negotiation example. Organizational Behavior and Human Decision Processes 63 
(1): 87-97.

Leuz, Christian and Robert E. Verrecchia. 2000. The economic consequences of increased disclosure. Journal of Accounting Research 38 (3): 91-124.

Maines Laureen A. and James M. Wahlen. 2006. The nature of accounting information reliability: Inferences from archival and experimental research. Accounting Horizons 20 (4): 399-425.

Markovits, Henry and Guilaine Nantel. 1989. The belief-bias effect in the production and evaluation of logical conclusions. Memory \& Cognition 17 (1): 11-17.

Matsumoto, Dawn A. 2002. Management's incentives to avoid negative earnings surprises. The Accounting Review 77 (3): 483-514.

Mercer, Molly. 2005. The fleeting effects of disclosure forthcomingness on management's reporting credibility. The Accounting Review 80 (2): 723-744.

Millar, Murray G. and Karen U. Millar. 1997. The effects of cognitive capacity and suspicion on truth bias. Communication Research 24 (5): 556-570.

Moore, Don A., Samuel A. Swift, Zachariah S. Sharek, and Francesca Gino. 2010. Correspondence bias in performance evaluation: Why grade inflation works. Personality and Social Psychology Bulletin 36 (6): 843-852.

Nisbett, Richard E. and Timothy D. Wilson. 1977. Telling more than we can know: Verbal reports on mental processes. Psychological Review 84 (3): 231-259.

Phillips, Lawrence D. and Ward Edwards. 1966. Conservatism in the simple probability inference task. Journal of Experimental Psychology 72 (3): 346-354.

Piotroski, Joseph D. and Darren T. Roulstone. 2004. The influence of analysts, institutional investors, and insiders on the incorporation of market, industry, and firm- 
specific information into stock prices. The Accounting Review 79 (4): 1119-1151.

Reb, Jochen. 2008. Regret aversion and decision process quality: Effects of regret salience on decision process carefulness. Organizational Behavior and Human Decision Processes 105 (2): 169-182.

Richardson, Scott, Irem Tuna, and Peter Qysokcki. 2010. Accounting anomalies and fundamental analysis: A review of recent research advances. Journal of Accounting and Economics 50 (2-3): 410-454

Rogers, Jonathan L., and Phillip Stocken. 2005. Credibility of management forecasts. The Accounting Review 80 (4): 1233-1260.

Ross, Lee, Mark R. Lepper, and Michael Hubbard, M. 1975. Perseverance in selfperception and social perception: Biased attribution processes in the debriefing paradigm. Journal of Personality and Social Psychology 32: 880-892.

Russo, J. Edward, Victoria Husted Medvec, and Margaret G. Meloy. 1996. The distortion of information during decisions. Organizational Behavior and Human Decision Processes 66 (1): 102-110.

Schkade, David A. and Eric J. Johnson. 1989. Cognitive processes in preference reversals. Organizational Behavior and Human Decision Processes 44 (2): 203-231.

Schipper, Katherine. 2007. Required disclosures in financial reports. The Accounting Review 82 (2): 301-326.

Securities and Exchange Commission (SEC). 2003. Interpretation: Commission guidance regarding management's discussion and analysis of financial condition and results of operations. Release nos. 33-8350; 34-48960, December 29. $<$ http://www.sec.gov/rules/interp/ 33-8350.htm>.

Seta, John J., Todd McElroy, and Catherine E. Seta. 2001. To do or not to do: 
Desirability and consistency mediate judgments of regret. Journal of Personality and Social Pyschology 80 (6): 861-870.

Slovic, Paul, Dale Griffin, and Amos Tversky. 1990. Compatibility effects in judgment and choice. In R. M. Hogarth (Ed.), Insights in decision making: A tribute to Hillel J. Einhorn (pp. 5-27). Chicago: University of Chicago Press.

Stein, Jeremy C. 1989. Efficient capital markets, inefficient firms: A model of myopic corporate behavior. The Quarterly Journal of Economics 104 (4): 655-669.

Towry, Kristy L. 2003. Control in a teamwork environment-The impact of social ties on the effectiveness of mutual monitoring contracts. The Accounting Review 78 (October): 1069- 1095.

Trueman, Brett, and Sheridan Titman. 1988. An explanation for accounting income smoothing. Journal of Accounting Research 26 (Supplement): 127-139.

Tversky, Amos and Daniel Kahneman. 1974. Judgment under uncertainty: Heuristics and biases. Science 185 (4157): 1124-1131.

Tversky, Amos, Shmuel Sattath, and Paul Slovic. 1988. Contingent weighting in judgment and choice. Psychological Review 95 (3): 371-384.

Verrecchia, Robert E. 2001. Essays on disclosure. Journal of Accounting and Economics 32 (1- 3): 91-180.

Wilson, Timothy D. and Samuel Lindsey and Tonya Y. Schooler. 2000. A model of dual attitudes. Psychological Review 107 (1): 101-126. 


\section{Vita}

James Smith was born in Edmonton, Alberta in 1979. James attended high school in Magrath, Alberta. In May 2003 he graduated from the University of Lethbridge with a Bachelor of Science. After graduation, James worked for Grant Thornton LLP in Calgary, Alberta. In August 2005, he completed his Master of Professional Accounting at the University of Saskatchewan. In May 2007, James received his Chartered Accountant designation in the province of Alberta. James entered the Graduate School of Business at the University of Texas at Austin in July 2007 and was awarded the Harrington Doctoral Fellowship. After completing his degree requirements, he joined the faculty at the University of Saskatchewan.

Permanent email: James.Smith@utexas.edu

This dissertation was typed by the author. 